\title{
THE
}

\section{INSTITUTION OF LOCOMOTIVE}

ENGINEERS, LONDON.

\section{The Internal Disturbing Forces in and Balancing of Locomotives (with special reference to three- and four-cylinder Engines).}

BY

E. L. AHRONS, M.I.Mech.E., Vice-President,

Nottingham.

TWENTY-NINTH PAPER

(OF TRANSACTIONS).

\section{SESSION 1914.}

To be Read on Saturday, October 3Ist, 1914

(Unless otherwise arranged),

at Caxton Hall, Victoria Street, Westminster.

\section{LONDON :}

7ublistred by the Jutatifutian.

1914.

Price Two Shillings Net. 


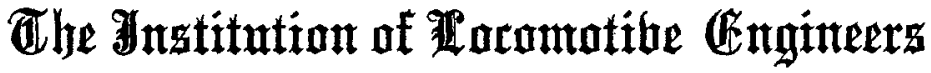

PAPER No. 29.

\section{The Internal Disturbing Forces in and Balancing of Locomotives (with special reference to three- and four-cylinder Engines).}

BY

E. L. AHRONS, M.I.Mech.E., Vice-President.

The number of three- and four-cylinder locomotives is so rapidly increasing that the author thinks that an analysis of the disturbing forces in, and the balancing of, these engines, as compared with two-cylinder engines, may be of some interest to the members of this Institution. It had been his original intention to deal with three- and fourcylinder engines only, but in the course of writing the paper he found it difficult to omit so many references to the ordinary two-cylinder engine that he decided to include all three types.

Appendix Tables I. to IV. give the list of three- and four-cylinder engines in use in this country at the end of 1913. It may merely be mentioned that the multi-cylinder engine is an old idea. In 1846 Messrs. Stephenson and Co. built a "single" express engine for the York, Newcastle and Berwick Railway (now the N.E.R.), with 6ft. 6in. driving wheels, and which had two outside cylinders $10 \frac{1}{2}$ in. by 2 in., and one inside cylinder I6in. by I8in.

On the Continent of Europe, the four-cylinder engine is very general, especially in France, where it is standard. There are, however, only a few engines with three cylinders, viz., some passenger engines in Switzerland, and some tank engines for local traffic in Germany and Italy. 


\section{Internal Disturbing Forces.}

I. Those produced by revolving masses.

II. Those produced by momentum of reciprocating masses.

III. Those produced by the pressure at the slide bars, and the opposite thrust at the crank axle.

IV. Those caused by the central line of the crank axle not in the same horizontal plane as the draw gear.

Each set may be resolved into a force and a "couple."

I. The revolving masses, if unbalanced, would produce pitching and rolling vertically, and surging and swaying horizontally.

As they can be, and usually are, perfectly balanced by the addition of counterweights, by the methods well known to the members, it is not necessary to discuss these at length.

II. The disturbances caused by the reciprocating masses cannot be perfectly balanced in a two- or threecylinder locomotive (and only balanced perfectly under certain special conditions in a four-cylinder locomotive), without introducing an imperfectly balanced revolving mass. Their effects are :-

(a) A fore and aft surging force of the value per cylinder of $\frac{W_{\omega^{2} r}}{g}\left(\operatorname{Cos} \theta+\frac{\operatorname{Cos} 2 \theta}{n}\right)$ where $W$ is the weight of the reciprocating parts, $\omega$ the angular velocity of the crank of radius $r$, and $\theta$ is the angle which the crank makes with the horizontal. This surging causes an irregularity of the draw bar pull and strains the couplings.

(b) The combined surging forces for each set of reciprocating parts, acting in the different planes of the several cylinders, cause a swaying movement in a horizontal plane about a vertical axis, passing through the mass centre of the engine. They also produce part of the disturbances under heading IV.

With regard to the fore and aft surging, it is of interest to recall that this was particularly apparent in the now defunct three-cylinder L. and N.W.R. compounds designed by Mr. Webb. These engines had the big L.P. piston, 3 oin. diameter, acting on the centre line of the engine. 
When starting, and for a considerable time after the start, these engines produced a fore and aft movement which could nearly always be felt throughout a long train, and was very unpleasant in the front coaches. If the engine started without slipping, this surging action would be due to the irregular turning moment of a single cylinder. But as violent slipping was almost invariably the case, there was then added the surging effect of the large partially unbalanced mass of a zoin. piston, etc., reciprocating at a high speed.

The surging action in the case of these engines was very irregular, as the two pairs of driving wheels were uncoupled, so that there was an absence of synchronism between the disturbance caused by this large L.P. piston, and those caused by the smaller outside reciprocating parts. In the modern three-cylinder engines, the piston diameter of the central cylinder varies from I 5 in. to Igin. only, and, moreover, the wheels are coupled. The surging motion is therefore less in extent and more regular.

III. Vertical disturbances produced by the pressure on the slide bars.

These cannot be balanced and their effects can be mitigated only by the stiffness of the springs. Further on the author has investigated them for one case, as a matter of interest. They vary for every portion of the stroke, and in the case of an engine running chimney first, they act upwards throughout near'y the whole of the stroke. For each single cylinder they can act downwards at the end of the stroke, when the retarding force of the reciprocating parts overcomes the effective steam pressure. But since the total lifting force produced by them on the engine at any instant is the sum of the instantaneous values of the lifting forces on all the slide bars, the very small downward force mentioned is much more than neutralised by the upward effect on the other slide bars, and the engine as a whole is lifted at the front end. The load on the leading springs is reduced and that on the driving springs may also be reduced, though to a less extent. The weight on the trailing wheels is correspondingly increased, and the resultant variation in the sum of these lifting forces causes a slight pitching of the engine. To resist this or any pitching action, the author considers that plate springs at the leading end are preferable to spiral springs, for the friction between the plates of the former type absorb some of the motion, whereas spiral springs have no such frictional resistance, and are extremely 
sensitive to change of load. The author has in mind certain express engines in which the "pitching" of the engine is extremely apparent to an observer watching them approaching and running through a wayside station. These engines have spiral springs for the leading bogie.

If $P$ be the total instantaneous effective steam pressure on the piston, and $P^{1}$ the equivalent instantaneous pressure (calculated as total lbs. on the piston) due to the momentum of the reciprocating parts, the total vertical pressure at any instant is $\left(P \pm P^{1}\right)$ tan $\phi$, where $\phi$ is the angle which the connecting rod makes with the piston rod. $P^{1}$ must be taken as negative during acceleration and as positive during retardation. If the centre line of cylinders is inclined to the horizontal $a$ a correction must be made by substituting $\left(P+P^{1}\right) \tan \phi \operatorname{Cos} a$ as the vertical component.

In reality the vertical pressure at the slide bars is accompanied by an equal and opposite vertical pressure at the axle acting downwards, and it is the varying moment of this couple which tends to turn the engine and cause a "galloping" action.

IV. Disturbances caused by the centre line of crank axle not in same horizontal plane as the draw gear.

The varying horizontal surging force caused by the reciprocating parts is transferred to the draw gear, and produces a "pitching" couple if the draw gear is not in the same horizontal plane as the centre of the driving axle. See Fig. $I$, in which the couple is $F a$. In express engines the arm $a$ of this couple is small, and in the Midland threecylinder compound engines mentioned later is about three inches only. In a mineral engine with small wheels, such as Webb's compound eight-coupled coal engines, $a$ is about $22 \mathrm{in}$. The couple varies in magnitude and direction, and the effect of it is a "galloping" action about the driving axle. Moreover, the draw bar pull, which varies in magnitude, though not in direction, has also to be similarly transferred, through the distance $a$, and this produces an additional couple. If the draw bar centre line is above that of the crank axle as in Fig. I, the leading end of the engine will be lifted, and the trailing end depressed on the springs. The opposite effect will take place if the draw bar gear happens to come below the centre of the crank axle.* These couples would be entirely eliminated if the centre lines of draw gear and crank axle coincided. This can be arranged

* In the G.N.R. 8ft. singles, of Mr. P. Stirling's design, the draw bar gear was about 6in. below the centre of the driving axle. 
for certain express engines, but is not practicable for standard gauge engines with small wheels. The pitching and galloping effects mentioned under this head are taken up by the springs.

As a means of dealing with comparative points the author thinks it most convenient to work out a concrete example, and for this purpose he has selected one of the three-cylinder compound engines of the Midland Railway. For the details of weights, etc., given below he is indebted to the kindness of Mr. Hy. Fowler, Past President of this Institution.

This engine is arranged with one inside H.P. cylinder $19^{\prime \prime} \times 26^{\prime \prime}$, and two outside L.P. cylinders each $21^{\prime \prime} \times 26^{\prime \prime}$, and the cranks are arranged as shown in Fig. 2.

Outside Cylinders (L.P.).

$\begin{array}{lllllll}\text { Centre to centre } & \ldots & \ldots & \ldots & \ldots & \ldots & 6 \mathrm{ft} . \\ 3\end{array}$ in.

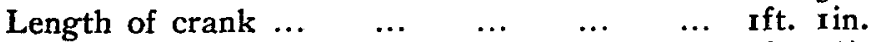

Length of connecting rod $\quad \ldots \quad \ldots \quad \ldots \quad 7 \mathrm{ft}$. $2 \frac{1}{2} \mathrm{in}$. Ratio of connecting rod
to crank $\ldots$

Weight of connecting rod:-

One-third reciprocating $\quad \ldots \quad \ldots \quad$ 1 2olbs. $\}=360 \mathrm{lbs}$.

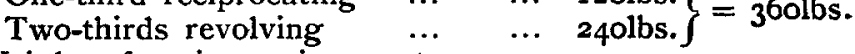

Weight of reciproonting parts :-

$\begin{array}{ll}\text { Piston, crosshead and attachments } & 590 \mathrm{lbs} . \\ \text { One-third weight of rod as above... } & \text { I 2olbs. }\end{array}=7$ rolbs.

Weight of revolving parts :-

Crank, crank pin and boss... ... 21 Ilbs.

Two-thirds connecting rod... $\quad \ldots . \quad 240$ lbs. $\}=601$ lbs.

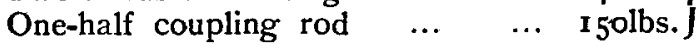

Inside Cylinder (H.P.).

$\begin{array}{llllll}\text { Length } \text { of } \text { crank } \ldots & \ldots & \ldots & \ldots & \ldots & \text { rft. } \text { rin. }\end{array}$

Length of connecting rod $\quad \ldots \quad \ldots \quad \ldots \quad 7^{\mathrm{ft}}$. $2 \frac{1}{2} \mathrm{in}$. Ratio of connecting rod
to crank $\ldots$

Weight of connecting rod :-

Two-thirds revolving $\ldots$
Weight of reciprocating parts :-

Piston, crosshead and attachments $49 \mathrm{olbs} . \zeta=650 \mathrm{lbs}$

One-third connecting rod ... ... I6olbs. $f=650$ olbs.

Weight of revolving parts :-

$\begin{array}{lll}\text { Crank, crank pin and arms } & \cdots & 5^{2} 5^{\mathrm{lbs}} . \\ \text { Two-thirds connecting rod... } & \cdots & 3^{20 l b s} .\end{array}=845^{\mathrm{lbs}}$. 
On these engines two-thirds of the reciprocating masses have been balanced by counterweights, viz. :-

$\begin{array}{llll}\text { For each outside motion } & \ldots & \ldots & 473 \frac{1}{3} \text { lbs. } \\ \text { For the inside motion } & \ldots & \ldots & 433 \frac{1}{3} \text { lbs. }\end{array}$

Two-Cylinder Locomotives (Outside Cylinders).

In order to have a basis for comparison it may be as well to first consider the engine as a two-cylinder engine with outside cylinders only, by the suppression of the inside cylinder, using the weights and dimensions given above for the outside cylinders. The effect of the subsequent addition of the third cylinder is then investigated.

The method used for finding the balance weights is the graphical one of Prof. Dalby, fully explained by him in a paper read before the Institution of Mechanical Engineers in November, Igor. All masses are taken as rotating at I3 inches crank radius. In drawing the moment and force polygons from the data given in Fig. 3, the plane No. 5 containing the inside cylinder has been suppressed in the consideration of the engine as a twocylinder engine. The reference plane is taken at No. 4 , the plane in which the L.H. balance weight rotates. Some explanation is necessary as to the figures in column II. of Schedule I. At plane No. I there rotate 15 olbs. coupling rod + Iglbs. portion of the crank pin. At No. 2 plane there are three masses, viz., 473.3 lbs reciprocating +24 olbs. (equal to two-thirds of the connecting rod) $+3^{2 l b s}$. portion of crank pin. In No. 3 plane is the centre of gravity of the rotating part of the boss of the wheel, the weight of which amounts to 160 lbs. at 13 in. radius and has been obtained by deducting the calculated $3^{2}+19=5$ rlbs. for the pins, from the 2 rilbs. total given in the preceding data.

The following is the schedule from which the moment and force polygons have been made, and reference should also be made to Fig. 3. for the explanation of the distances given in column I. For further particulars of the method employed, those members unacquainted with it should refer to Prof. Dalby's paper (Proc. Inst. Mech. Engrs., rgor). 
SCHEDULE I.

FOUR WHEELS COUPLED OUTSIDE CYLINDER EXPRESS ENGINE.

Two Cylinders.

Reference Plane at No. 4.

See Figures 3, 4, 5 and 6.

I.

$\underset{\text { of }}{\text { Number }}$

Crank.

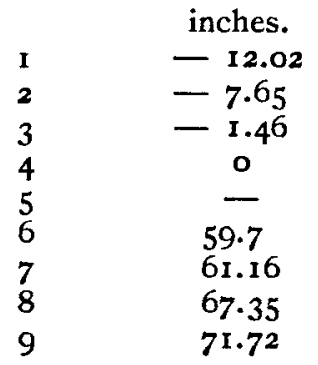

II.

Equivalent

Masses at $13^{\prime \prime}$

Crank Radius.

Ibs.

I69

$745 \cdot 3$

160

(1 218 )

$\left(\frac{72 \frac{7}{5} \frac{0.0}{8}{ }^{\circ}=}{160}=1218\right)$
745.3
169
III.

Equivalent

Mass

Moment.

pounds-inches.

- 2031

- 5701

$-233$

(72700)

9786

50196

I 2121

The quantities in brackets are those found by measurement of the closure lines of the polygons. The negative quantities are those on the opposite side of the reference plane 4 , the moments of which act in the opposite direction to those on the other side of the reference plane.

The total balance weight found is r,2r8lbs. acting at $\frac{1}{1} \frac{3}{2} \mathrm{ft}$. radius. The actual balance weights in the wheel would be placed at a radius of about $2 \mathrm{ft}$. $7 \mathrm{~B}$ in. for the centre of gravity from the centre of the wheel, this being the approximate radius for a $7 \mathrm{ft}$. wheel, and the amount of the balance weight actually in the rim would be $1,218 \times \frac{13}{31 \frac{3}{5}}$

In using this balance weight we have balanced all the "revolving" disturbances, but we have left one-third of the "reciprocating" disturbances unbalanced. But we have also introduced a new " revolving " disturbance, as the portion of the balance weight used for balancing the " reciprocating" disturbances can only do so in the line of action of the cylinder centre line, which will be supposed to be horizontal. This portion of the weight, however, has a centrifugal component in a vertical direction, which is unbalanced, and causes rolling of the engine, and also what is popularly termed "hammer blow" on the rails. 
The amount of " reciprocating" balance in the above case is $538 \mathrm{lbs}$. out of the $1,2 \mathrm{I} 8 \mathrm{lbs}$. total at $\mathrm{I} 3 \mathrm{in}$. radius, and can be found either by calculation or by drawing another polygon.

At 70 miles per hour, a $7 \mathrm{ft}$. wheel makes 240.1 revolutions per mile, and 4.66 revolutions per second. Therefore the number of radians per second $(\omega)=\frac{4.66 \times 360}{57.3}$ and the crank radius $r$ being $\frac{13}{12} \mathrm{ft} . \frac{\omega^{2} r}{g}=28.9$ nearly.

The centrifugal force of the $5381 \mathrm{bs}$. "reciprocating portion " of the balance weight is

$$
\frac{W \omega^{2} r}{g}=\frac{53^{8} \times 28.9}{2,240}=6.94 \text { tons. }
$$

This force acts with full effect vertically when the balance weight is at the top or the bottom of the wheel. In the first case it decreases the weight of the wheel on the rail, and in the second it makes the wheel press with extra force on the rail. If we suppose ig tons static load on the driving wheels $(=9.5$ tons per wheel $)$, we have $9.5-6.94$ $=2.5^{6}$ tons only, pressure between the wheel and the rail when the balance weight is at the top, and $9.5+6.94=$ 15.44 tons when the weight is at the bottom, and the pressure during one revolution will vary between these amounts according to a curve of sines. If this pressure is too small, slipping will result. On the other hand, the balance weight in the other wheel (say the R.H.) is $103^{\circ}$ in front of it, and when the L.H. weight is at the top, the R.H. weight is moving downwards and producing a force of $6.94 \times$ Sin $13^{\circ}=6.94 \times .225=1.56$ tons acting downwards. We therefore find that the R.H. wheel in this position is exercising a pressure of $9.5+\mathrm{I} .56=\mathrm{I} \mathrm{I} .06$ tons. If we take the coelficient of friction at $\frac{1}{6}$, the resisting force at the circumference of the L.H. wheel is $\frac{2.5^{6}}{6}=.427$ ton, and that at the circumference of the R.H. wheel is $\frac{\mathrm{I} \text {. } 06}{6}=\mathbf{I} .8_{43}$ tons, a difference which throws a great twisting stress on the axle.* Referring to the effect of such an inequality of the resisting forces at the rims of the two wheels, the author calls to mind an extreme case, which, though not due to balancing, may illustrate such effect. A goods

* With sand and very dry rails, this difference and consequent stress may be almost doubled. 
engine was starting a fairly heavy train up a bank with the rails greasy, and sand was applied. Unfortunately, the sand on one side did not run, and the driving wheel on the cpposite side suddenly gripped the rail, with the result that the crank axle was sheared through. There may have been contributcry causes, such as a hidden flaw.

If the centrifugal force $\frac{W \omega^{2} r}{g}$ of the " reciprocating" portion of the balance weight exceeds the load on the driving wheel, this wheel will lift, and cause an actual hammer blow when it drops on to the rail again. This will take place when $\frac{W \omega^{2} r}{g}=9.5 \times 2,240 \mathrm{lbs}$, , and working this out for the particular two-cylinder engine under consideration, it will be found that the wheel will lift when the speed reaches 81.8 miles per hour, a speed by no means uncommon in practice. The question of improving this condition by distributing the reciprocating portion of the balance weight between the coupled wheels will be mentioned later.

In addition to the lifting effect mentioned above, the same force acting alternately on either side of the engine produces a rolling action. The amount of the couple producing this can be calculated, but its effect on the engine as a whole cannot be estimated, as the force producing it is mostly taken up by the springs, and it depends upon the condition and stiffness of the latter as to how much effect is felt on the body of the engine.

There remains a consideration of the effect of the onethird portion of the reciprocating masses, which has been left unbalanced. The maximum fore and aft surging produced by these can best be obtained from the graphs shown in Fig. 9. The surging force for each cylinder varies as the expression

$$
\frac{W \omega^{2} r}{g}\left(\operatorname{Cos} \theta+\frac{\operatorname{Cos} 2 \theta}{n}\right)
$$

which takes into account the effect of the obliquity of the connecting rod. $\theta$ is the angle which the crank makes with the centre line of the cylinders, and $n$ is the ratio connecting rod which is equal to 6.65 in the engine under consideration. Neglecting the obliquity of the connecting rod, the surging force would vary as $\operatorname{Cos} \theta$ simply. (It will be pointed out later that in a two- or a four-cylinder engine the obliquity of the connecting rod does not affect the 
surging forces, for the so-called " secondary disturbances" due to it mutually cancel one another for an even number of cylinders. As, however, it influences the surging force in a three-cylinder engine, and exercises a very considerable effect on the swaying moments for engines with either two, three, or four cylinders, the full expression, including $\frac{\operatorname{Cos} 2 \theta}{n}$ has been retained throughout this paper).

In Fig. 9 the ordinates of Curve I. represent the surging force through one revolution for the R.H. side. Ordinates above the horizontal zero line show the forward-acting force, and those below the backward-acting force. Curve II. shows the same for the L.H. cylinder, which is $90^{\circ}$ behind. Curve III. is the resultant obtained by combining I. and II. The scale to the left shows surging forces before balance weights have been added. The maximum value of III. is 29,00olbs. forward at $45^{\circ}$, and the same amount backward at $225^{\circ}$. (These angles denote the position of the leading crank.) The position of the cranks and balance weights when the R.H. crank is at $45^{\circ}$ is shown in Fig. 4A. The sum of the two forces $F_{R}$ and $F_{L}$ is as given above, 29,ooolbs., and the sum of the two opposite balancing forces $B_{R}$ and $B_{L}$ is $2 \times \frac{W_{\mathbf{r}^{2}}{ }^{2} r}{g} \operatorname{Cos} 5^{1^{\frac{1}{2}}}{ }^{\circ}$ where $W_{\mathbf{r}}$ is the portion of the balance weight due to balancing two-thirds of the reciprocating masses. For 70 miles per hour (the speed corresponding to the curves, Fig. 9) the above expression gives 19,35 olbs., so that the remaining unbalanced surging force is 9,65 olbs. ( $4 \cdot 308$ tons).

In considering the swaying moment produced by these forces acting on opposite sides of the engine, note must be taken that the forward-acting force on the R.H. side and the backward-acting force on the L.H. side turn the head of the engine " counterclockwise," and the forces in the reverse direction have a "clockwise" moment. Curve VI. has been drawn by taking similar turning forces from Curves I. and II. multiplied by the distance $\frac{6 \mathrm{ft} .3^{\text {in. }}}{2}=3.125 \mathrm{ft}$. from one outside cylinder to the centre line of the engine, and we obtain a maximum swaying moment of 97 , roolbs. $f$ t., which has to be partially counterbalanced. This maximum value obtains in a clockwise direction, when the R.H. crank is at about $116^{\circ}$ and the L.H. crank at about $26^{\circ}$. If the "obliquity" effect 
were neglected, the angles would be R.H. $135^{\circ}$, and L.H. $45^{\circ}$.

In Fig. $4^{B}$ the balance weights are opposing this turning moment by tending to turn the engine counterclockwise. Each weight is $\frac{1}{2} \times \frac{59.7}{12}$ feet from the centre line of the engine, and the moment of the two weights combined is $\frac{W_{\mathrm{r}} \omega^{2} r}{g} \times \frac{59 \cdot 7}{24}\left(\operatorname{Cos} 53 \frac{1}{2}^{\circ}+\operatorname{Cos} 23 \frac{1}{2}^{\circ}\right)^{*}$

Note that $53^{8} \times 28.9 \times \frac{24}{59.7} \times 1.5^{12}=5^{8,480 l b s}$ feet nearly.

The final maximum swaying moment after balancing $\frac{2}{3}$ of the reciprocating masses is therefore $97,100-58,480=$

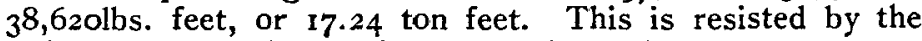
weight of the engine resting on the journals.

\section{Two-Cylinder Engines with Inside Cylinders.}

If we transfer the two outside cylinders to the inside, and place them, say, at $2 \mathrm{ft}$. Iin. centre to centre, making no change in the relative arrangement of cranks and coupling rods, we obtain an engine on what may be termed the "Stroudley system," with the inside connecting rod and the outside coupling rod cranks pointing in the same direction. The surging forces for the inside-cylinder engine will remain exactly as in the previous case, if the weights of the inside reciprocating parts were the same as those of the outside-cylinder engine. The swaying moments would, however, be reduced in the proportion of $2 \mathrm{ft}$. Iin. to $6 \mathrm{ft}$. 3 in. -i.e., to one-third, and the maximum value (unbalanced) would be $\frac{97,100}{3}=3^{2,3661 b s .-f t}$.

In the following example the weight of the inside cylinder reciprocating masses has been taken as $65 \mathrm{olbs}$.i.e., that of the third inside cylinder, rgin. diameter, of the Midland engine, as this weight has also been used for the four-cylinder engine. The revolving masses are supposed to be $845 \mathrm{lbs}$. The surging force would therefore be reduced from 29,000 lbs. to about 26,55 olbs., and the above swaying moment from 32,366 to 29,65 olbs.-ft. In the "Stroudley"

* Note that these are the angles of the combined total balance weight. For an outside cylinder engine the angles which the reciprocating component would make are almost the same as those for the whole balance weight. 
balanced engine the total balance weight would be equivalent to $\mathrm{I}, 3 \mathrm{I}$ I ibs. at $\mathrm{I} 3 \mathrm{in}$. radius, placed at an angle of $15^{\circ}$ with the direction of the crank produced. If the engine had the usual arrangement of inside and outside cranks opposite one another, the balance weight would be only $678.4 \mathrm{lbs}$. at an angle of about $35^{\circ}$ with the direction of the crank produced. In both cases that portion of the weight due to the reciprocating masses would be $33^{2 .} 5^{1 b s}$. at $\mathrm{I} 3 \mathrm{in}$. radius, and this component would, if separated from the total balance weight, act at an angle of about $221^{\circ}$. The "hammer effect," which is entirely due to the vertical component of this portion, is the same in both cases.

This point has been emphasised at length, because the author has seen it wrongly argued that the larger Stroudley balance weight must cause extra "hammer blow." Mr. Stroudley's reason for placing the outside and inside cranks on the same side of the axle is stated to have been that he observed, in the case of the outside cylinder engines on the Highland Railway, that the axle-boxes wore better. The thrust on the horn-blocks in this case is the difference between, instead of the sum of, the connecting and coupling rod thrusts, the latter being the condition when the inside and outside crank-pins are opposite to one another. But though the horn-block pressures are much smaller, the bending moment on the crank axle is much greater. This question, however, of the strength of crank axles is beyond the limits of this paper.

The final maximum swaying moment of the insidecylinder engine after balancing will be 29,650 lbs., less the opposite swaying moment of the balance weights, amounting to $33^{2.5} \times 28.9 \times \frac{59.7 \mathrm{in} .}{12 \times 2}\left(\operatorname{Cos} 821^{\circ}+\operatorname{Cos}\right.$ $\left.5^{21^{\circ}}\right)=$ about 17,850 lbs. $f$ t. The difference gives I I,80olbs.-ft. = about 5.26 ton-feet.

The maximum unbalanced vertical centrifugal force at 70 m.p.h. is $\frac{332.5 \times 28.9}{2,240}=4.285$ tons, so that the load on a wheel carrying 9.5 tons, as before, would be reduced to 5.215 tons, and increased to 13.785 tons during one revolution. There would therefore not only be less twisting strain on the axle than in the case of the outside cylinder engine, but more maximum weight available for adhesion, less hammer blow effect and very much less swaying moment. Only the fore and aft surging forces would with 
equal reciprocating masses remain as before. Moreover, the inside-cylinder engine can, other things being equal, attain a much higher speed--viz., I04. I miles per hourbefore the driving wheel is lifted from the rail.

\section{Three-Cylinder Engine-Midland Compound Type.}

The cranks of this engine are set as in Fig. 2, and as the total weight- $845 \mathrm{lbs}$. - of the revolving masses at the inside crank pin is so arranged that it is the resultant of the two separate revolving masses, each 6oilbs., at the outside crank pins, these forces balance. But the couples produced do not balance, and therefore a counterweight for the revolving masses is required.

Figs. 2 and 3 give the data, Schedule 2 the quantities, Fig. 7 the mass moment polygon, and Fig. 8 the force polygon for the combined revolving and reciprocating masses.

\section{SCHEDULE II.-THREE-CYLINDER ENGINE.}

Cranks at $90^{\circ}, \mathrm{I} 35^{\circ}$ and $\mathrm{I} 35^{\circ} .^{*}$

Reference Plane at No. 4.

See Figs. 2, 3, 7 and 8.

I.

Number of Crank.

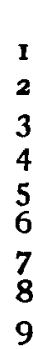

\section{Distance from}

Reference

Plane.

inches.

$-12.02$

$-7.65$

$-1.46$

0

29.85

59.7

61.16

67.35

71.72
II.

Equivalent Masses at $\mathbf{3}^{\prime \prime}$ Crank Radius.

lbs.

169

$745 \cdot 3$

160

$(962.3)^{*}$

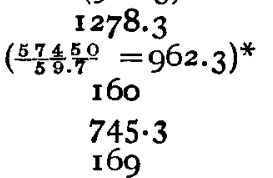

III.

Equivalent

Mass

Moment.

pounds-inches.

- $203 \mathrm{I}$

- 5701

$-233$

0

$$
\begin{gathered}
38157 \\
\left(5745^{\circ}\right)^{*} \\
9786 \\
50196 \\
\text { 12121 }
\end{gathered}
$$

* For three-cylinder engine with cranks at $120^{\circ}$ the above schedule applies except that the value in brackets opposite crank 4, Col. II., becomes 1,166 lbs., and opposite crank 6, Col. II., $\frac{69600}{59.7}=1,166$, and Col. 111., 69,600. See Figs. 10, II and 12. 
Calculated from these data, the balance weight is 962.3lbs. at 13 in. radius. Of this the reciprocating portion, calculated from the dotted line polygon in Fig. 7 is $437 \mathrm{lbs}$. This weight gives a vertical centrifugal force of $\frac{437 \times 28.9}{2,240}=5.59$ tons. The static weight on each driving wheel is $\frac{19.576}{2}=9.788$ tons, so that at 70 m.p.h. the rail pressure in each revolution will vary from 15.377 tons maximum to 4.199 tons minimum and the driving wheel will lift at 92.16 miles per hour.

In Fig. 9, curve IV. shows the surging force produced by the third central cylinder, and if its ordinates be added to those of curve III. (which is the total for the two outside cylinders), the combined sum is given by eurve V. From this curve it is evident that by adding the third cylinder the surging force has been considerably reduced and is a maximum of $\mathrm{r}_{3}, 040 \mathrm{lbs}$. forward, and $7,455 \mathrm{lbs}$. backward, the difference being due to the obliquity of the connecting rods. But the addition of the third cylinder has not affected the swaying moments, which remain the same as in the two- (outside) cylinder engine. This is obvious as the moments of the forces produced by the third cylinder about the centre line of the engine are nil.

On the other hand the effect of the reciprocating portions of the balance weights (each $437 \mathrm{lbs}$.) is different. Fig. 8a shows the positions of the cranks and " reciprocating" balance weights at the point of maximum forward surging force. The effect of the two weights is $2 \frac{W_{\mathrm{r}} \omega^{2} r}{g}$ $\operatorname{Cos} 74 \frac{1}{2}^{\circ}$, and for 70 miles per hour $=6,740 \mathrm{lbs}$. The resultant unbalanced surging force is $6 ; 3$ oolbs. In the same manner, if the clockwise swaying moments, when the R.H. crank is at $120^{\circ}$ (Fig. 8b) are counteracted by the counter-clockwise moments of the balance weights, we get $97,100-58,390=38,7$ Iolbs. ft., which is almost the same as for the outside two-cylinder engine. (As in the previous cases, two-thirds of the reciprocating masses are supposed to be balanced.) But the three-cylinder engine has the advantage of a higher critical speed of 92.16 as against 81.8 miles per hour for the two-cylinder engine.

Three-Cylinder Engine with Two driving Axles.

This case is that of the Great Central three-cylinder engines. The cranks of the compounds are set at the same 
angles as those of the Midland engines, but on different axles, and the coupling rods maintain the proper angular positions.

If the balance weights were found by treating each of the two driving axles as part of a separate engine, for the two outside cylinders we should have a schedule the same as that of the two-cylinder engine already given, and the second driving wheels connected to the outside cylinders would have large balance weights, the same as for that engine, viz, , $x, 2$ I $81 \mathrm{bs}$. at 13 in. radius, with all the attendant disadvantages. There would also be additional balance weights of $4981 \mathrm{bs}$. in the wheels of the first (inside) driving axle. The error in this method lies in that unnecessarily large balance weights are introduced, because no account has been taken of the fact that the masses of the third inside cylinder have themselves a partial balancing effect on those of the outside cylinders in so far as the revolving masses and the surging forces are concerned.

The proper method of treating an engine of this class is to completely balance the revolving masses, each set on its own axle; i.e., consider the engine as two separate engines, insofar as the revolving masses only are concerned.

The reciprocating masses can then be taken together as for one engine.

Using the same masses and dimensions as for the Midland engine, we should have a "reciprocating" balance weight of $437 \mathrm{lbs}$. and this can be divided between the first and second driving wheels either equally, or in the proportion of the weights on those wheels, in order that the critical speed at which they lift should be the same for both wheels.

The reason for the above is that the reciprocating masses surge and sway the engine as a whole in a horizontal plane, whereas the vertical components of the revolving masses act on the springs of each driving axle independently.

If the balance weight of $437 \mathrm{lbs}$. is divided, the critical speed will be so high as not to require further consideration, and it may be noted that the same result could be attained in the Midland engine by similarly dividing the "reciprocating portion" of the balance weight.

Three-Cylinder Engine-Cranks at $120^{\circ}$.

The North-Eastern engines are in general arranged with cranks at $120^{\circ}$, so that the outside coupling rods are not at 
right angles as is usual. For the express engines one driving axle is employed. In considering the effect of this alteration, in the first place if we wish the revolving forces to balance each other, and we assume the outside cylinders to have revolving masses of 6orlbs. exactly as in the previous case, the inside revolving mass would have to be 60 lbs. also, instead of $845 \mathrm{lbs}$. as previously. This might be difficult to arrange in the design, as the crank webs are heavy. Taking as a concrete example the weights given by Mr. Hughes (Proc. Inst. Mech. Engrs., 1909) for his engines on the L. and Y.R., which have equal r6in. $x 26$ in. cylinders inside and outside, the weight of the unbalanced portion of inside webs and crank pin is 57 olbs., whilst that of the unbalanced portion of the bosses and pins of the outside motion is only $224.3^{l b s}$, i.e., considerably less than half.

For this reason the standard example used throughout this paper for comparison will be used, i.e., the same revolving and reciprocating weights as in the case of the Midland three-cylinder engine, and the cranks merely altered to $120^{\circ}$. By this the author does not imply that the weights could not be reduced, because we have hitherto been dealing with those for an inside rgin. cylinder, whereas the three-cylinder high pressure express engine would probably be about I6in. On the other hand, it may be added that the total inside revolving parts for one of these L. and Y.R.

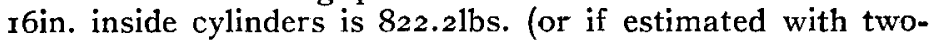
thirds of the connecting rod $858.6 \mathrm{lbs}$.), so that the $845 \mathrm{lbs}$. taken by the author is not over estimated.

Fig. Io shows the crank diagram, and Figs. II and 12 the mass-moment and mass polygons respectively for the engine with cranks at $120^{\circ}$. The schedule of masses and moments is exactly the same as Schedule II., except that the mass moment to be entered into column 6 , as found by polygon Fig. $I I$, is 69,600 and the resulting balance weight is $\frac{69,600}{59 \cdot 7}=1,1661 \mathrm{lbs}$. at 13 in. radius, of which $516.21 \mathrm{bs}$. balance two-thirds of the reciprocating masses. These figures compare with $962.3 \mathrm{lbs}$. and $437 \mathrm{lbs}$. respectively for the Midland engine with cranks at $90^{\circ}, 135^{\circ}$ and $135^{\circ}$. The critical speed, with a weight of 9.788 tons on each wheel as before, will be reduced to 84.0 miles per hour. For a fast express engine this is by no means high enough, and it would be preferable to distribute the $5^{161 b s}$. "reciprocating" balance weight be- 
tween the coupled wheels. Fig. I3 shows the surging forces and the swaying moments.

Comparing the two types of three-cylinder engine, the fore and aft surging forces are very much reduced by placing the cranks at $120^{\circ}$, so that the draw-bar pull will be steadier, aud this latter is again improved by the more even turning moment of cranks at $I 20^{\circ}$. The maximum surging force (Curve V., Fig. I3) is hardly perceptible, and is due only to the obliquity of the connecting rods. But the swaying moment is greatly increased, and the maxima occur when the R.H. crank is near $135^{\circ}$ and $345^{\circ}$. The positions of the cranks at this point are shown in Fig. ${ }^{1} 3^{B}$, as also the positions of the "reciprocating" portions of the balance weights derived from the dotted polygon in Fig. I I, the angle of the reciprocating component being $27^{\circ}$. Curve VI., Fig. I3, shows the maximum swaying moment of the combined R.H. and L.H. cranks to be about Ir7,00olbs. feet. The counter-effect of the balance weights is

$$
\frac{W_{\mathrm{r}} \omega^{2} r}{g} \times \frac{59.7}{2 \times 12}\left(\operatorname{Cos} 18^{\circ}+\operatorname{Cos} 12^{\circ}\right) \text {, }
$$

which for $516.25 \mathrm{lbs}$. and $70 \mathrm{~m} . \mathrm{p} . \mathrm{h} .=7 \mathrm{l}, 590 \mathrm{lbs} . \mathrm{ft}$. The resultant unbalanced swaying moment is $117,000-71,590$ $=45,4$ Iolbs. $-\mathrm{ft}$. (20.3 ton-feet). The same results occur when the R.H. crank is at $345^{\circ}$. The $R$. and L. balance weights (Fig. I $3^{\mathrm{B}}$ ) are so nearly opposite to one another that the resultant surging force is only slightly affected.

The North-Eastern Railway, in their three-cylinder express engines, balance approximately one-half of the weight of the reciprocating masses for the outside cylinders cnly, and divide this balance weight equally between the coupled wheels. The reciprocating parts for the inside cylinders are not balanced.

Taking the engine which we have been considering (but noting that the weights and dimensions differ from those of the N.E.R. engine), Figs. I4 and I5 show the results of balancing it according to the practice of the N.E.R. The reciprocating balance weights are each $425^{\frac{1}{2}}$ lbs. at $I 3$ in. radius, placed at the angles shown (supposing the whole balance weight concentrated in one wheel). Curve V. (Fig. I5) shows the unbalanced surging force, and Curve VI. the unbalanced swaying moments, both curves being taken from Fig. 13. The addition of balance weights at the angles shown in Fig. I4 at once alters the surging forces (Curve V.) for the worse, for these forces previously almost balanced each other. Curves L.B. 
and R.B. (Fig. 15) are those showing the surging forces now introduced by the left-hand and right-hand balance weights, and Curve T.B. is the total resultant of the two. If the ordinates of Curve V., the original surging force, be deducted from the ordinates of Curve T.B., we obtain curve S.F., the final surging force after the engine has been balanced. Considering the swaying, the curve B.M. shows the combined sum of the swaying moments of the two balance weights, clockwise moments being considered positive, and counter-clockwise moments negative. Deducting these from the curve of unbalanced swaying moment (VI.), we obtain Curve S.M., the final swaying moment after the engine has been balanced. This amounts to a maximum of about 62,500 lbs. feet $(27.9$ ton feet), as compared with 45,500 lbs. feet $(20.3$ I ton feet) when two-thirds of all three reciprocating masses are balanced. In addition, there is the introduction of a surging force.

By balancing one-half of the reciprocating masses for all three cylinders, the "reciprocating portions" of the balance weights would be reduced from $425 \frac{1}{2}$ lbs. to $3^{8} 7$ lbs. at $\mathrm{r}$ in. radius, and they would occupy the positions shown in Fig. 14A, very nearly opposite to one another, so that the surging force introduced would be negligible. The counter swaying moment of these two weights would be $387 \times 28.9 \times \frac{59.7}{24}\left(\operatorname{Cos} 17^{\circ} \times \operatorname{Cos} 13^{\circ}\right)=53,7$ oolbs. $\mathrm{ft}$. The final swaying moment of the engine would be 63,400 lbs. feet (28.25 ton feet), very slightly more than before. The variation of rail pressure would be somewhat improved in the ratio of $3^{8} 7$ to $4^{2} 5^{\frac{1}{2}}$.

Before leaving the question of three-cylinder engines, an inspection of the curves in Figs. 9 and $\mathrm{r}_{3}$ will show the undesirability of having multi-cylinder engines with uncoupled wheels. Curve III. showing the total surging force for two outside cylinders would be fixed, but Curve IV. could then take up any phase with respect to III., and in case it came into the same phase with it, a very marked surging action would result. This has already been alluded to in mentioning the Webb three-cylinder compounds. In fourcylinder uncoupled engines, such as those of the L. \& S.W.R. 720 class, the effects would be still worse, for not only could the surging curves come into phase, but as there are two extra cylinders, the swaying moments could also do the same, and it is conceivable that the results might, 
under unfavourable circumstances, border on the danger line; for it must be remembered that, in addition to the internal disturbing forces with which we are dealing, there are also more severe external disturbing forces caused by curves in the line, widened gauge, etc., which cause rolling and horizontal swinging, generally in longer and irregular periods. These might occasionally synchronise with the effects produced by the internal disturbing forces.

\section{Four-Cylinder Engines.}

Suppose equal reciprocating masses for each cylinder. Whatever the revolving masses are, they can always be perfectly balanced, so that these need not be further considered. Taking the Midland engine we have hitherto been considering, in order to afford some basis for comparison, the author supposes it to be converted into a four-cylinder engine, the cranks being set as in Fig. I6, with the R.H. outside crank leading the I.H. outside crank. This is similar to the usual arrangement generally adopted (except that the L.H. crank frequently leads). The inside and outside cranks on the same side of the engine are opposite to each other-i.e., $180^{\circ}$ apart. The reciprocating masses are taken to be 650 olbs. total for each cylinder. The surging forces worked out from the expression $\frac{W_{\omega^{2} r}}{g}(\operatorname{Cos} \theta+$ $\frac{\operatorname{Cos} 2 \theta)}{n}$ are given for a complete revolution in Table V., the speed being, as before, 70 miles per hour. It will be seen that these forces balance one another throughout, (the very slight differences being due to the approximate figures having been taken in calculation). But the swaying moments, which are of most importance, do not balance. This is explained by the fact that if the surging forces on the R.H. side are acting in the opposite direction to those on the L.H. or opposite side, the forces balance, but both sets are turning the head of the engine in the same direction, and their moments are cumulative, and must be added together. In Fig. I7, Curves I., II., and III. have been drawn from the above data. Curve I. represents the combined swaying moment of the two outside cylinders, which are $3.125 \mathrm{ft}$. from the centre line of the engine, and the cranks of which are at $90^{\circ}$ with one another. Similarly, Curve II. represents the swaying moment of the two inside cylinders, which are opposite in phase to the outside cylinder, and have a leverage of $1.042 \mathrm{ft}$. Curve III. is the combined resultant of the two curves, and gives the total swaying 
moment on the engine. This reaches a maximum of 68,54 olbs. feet.

If we balance the whole of the 65olbs. reciprocating masses, there would be a balance weight of $3^{8} 7 \mathrm{lbs}$. at 13 in. radius in each wheel (Fig. 16). The moment of each balance weight is $3^{8} 7 \times 28.9 \times \frac{59.7}{2} \times \frac{1}{12}$ lbs. feet, where as previously $28.9=\frac{W \omega^{2} r}{g}$ for 70 miles per hour, and $59.7 \mathrm{in}$. is the distance apart of the planes of the two balance weights. As the horizontal forces and moments produced by the balance weights always vary as $\operatorname{Cos} \theta$, we obtain curve of sines IV., which has a maximum value of 55.640 lbs.-ft., and is in such a phase that the combined balance weights are pulling the leading end of the engine in a clockwise direction when the swaying moment is counterclockwise.

Curve V. shows the final resultant swaying moment after the addition of the balance weight, and this reaches a maximum of 23,700 lbs. feet. The moment changes sign four times per revolution. If the balance weight of $387 \mathrm{lbs}$. is placed in the driving wheels-the four pistons being supposed to be connected to the same driving axle-and if the weight on one driving wheel be as before 9.788 tons, the critical speed at which the wheel would lift would be 97.9 miles per hour. If required to raise the critical speed, it might be preferable to balance less than the whole of the reciprocating masses, or divide the reciarocating pirtion of the balance weight between the coupled wheels.

\section{Four-Cylinder Engines with Two Driving Axles.}

The author has mentioned (in connection with the threecylinder engines with separate driving axles) that for the revolving masses the two driving axles must be considered independently, each having its own set of revolving masses. balanced on it. For the four sets of reciprocating masses, if these are balanced, they should be taken together as for one engine, and the balance weight formed can be divided over the two pairs of driving wheels.

The author has worked out the balance weights for the four-cylinder 4-6-0 engines of the Lancashire and Yorkshire Railway from data contained in the Proc. Inst. Mech. Engineers, 1909, and some additional particulars 
kindly furnished to him by Mr. G. Hughes, M.Inst.C.E., Chief Mechanical Engineer.

In these engines only the revolving masses are counterbalanced. The inside motion of the first driving axle is balanced as in Fig. 18 with counter-weights formed by the extension of the crank arms; the coupling rods are balanced in the rims of the wheels. The outside revolving masses for the second driving wheel, connected to the outside cylinders, are balanced entirely in the rims of the wheels. The revolving masses in these engines are:-

Inside Motion.

\begin{tabular}{lllll} 
& & & \multicolumn{1}{l}{ lbs. } \\
Connecting rod revolving portion & $\ldots$ & $2^{2 \cdot 3}$ \\
Unbalanced part of crank webs & $\ldots$ & $5^{1} 3$ \\
Part of crank pin $\quad \ldots$ & $\ldots$ & $\ldots$ & 57
\end{tabular}

822.3 lbs.

Outside Motion.

\begin{tabular}{|c|c|c|c|c|}
\hline Connecting rod, revo & & & & $\begin{array}{l}\text { lbs. } \\
187\end{array}$ \\
\hline Unbalanced part of $c$ & ank & & $\cdots$ & \\
\hline Part of crank pin & $\ldots$ & $\cdots$ & $\because$ & II 5.3 \\
\hline Part of coupling rod & $\ldots$ & $\ldots$ & $\ldots$ & $25^{8}$ \\
\hline
\end{tabular}

The outside revolving masses are completely counter-

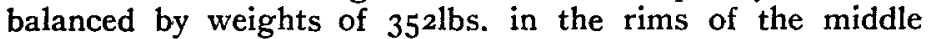
driving wheels, acting at a radius of $26 \frac{5}{8}$ in., and at angles as shown at L.B.R. and R.B.R. in Fig. 19, but for constructional reasons the small angle of $6^{\circ}$ has been neglected, and the balance weights placed exactly opposite to the outside cranks.

The reciprocating masses are not balanced; there is therefore no surging force, and no unbalanced vertical centrifugal force causing variation of rail pressure. There is, however, an unbalanced swaying moment, which could have been balanced at the expense of introducing a very small surging force, and a varying pressure on the rails. This has been worked out as per Schedule 4, and Figs. I9, 20 and 21 . These must be taken "diagrammatically," as they combine the reciprocating masses for all four cylinders on one axle. Fig. $2 \mathrm{I}$ is given to show the form which the polygons take for a four-cylinder engine. 
SCHEDULE IV.-RECIPROCATING MASSES ONLY. FOUR-CYLINDER ENGINE, L. \& Y.R.

\begin{tabular}{|c|c|c|c|}
\hline $\begin{array}{l}\text { Plane } \\
\text { No.* }\end{array}$ & $\begin{array}{l}\text { Distance from } \\
\text { Reference } \\
\text { Plane No. } 4 .\end{array}$ & $\begin{array}{c}\text { Masses } \\
\text { at } \\
\text { I3" Radius. }\end{array}$ & $\begin{array}{c}\text { Mass } \\
\text { Moments. }\end{array}$ \\
\hline & inches. & lbs. & lbs.-inches. \\
\hline $\begin{array}{l}I \\
4\end{array}$ & $-0^{12}$ & $\begin{array}{l}595 \cdot{ }^{25} \\
(444)\end{array}$ & $\begin{array}{c}7_{0}^{14} 43 \\
o\end{array}$ \\
\hline 5 & I 8.062 & $5^{24 \cdot 3}$ & $947^{\circ}$ \\
\hline 6 & 41.062 & $5^{24} \cdot 3$ & $2153^{\circ}$ \\
\hline 7 & 59.125 & $\left(\frac{26}{5} \frac{250}{2}=444\right)$ & $(26250)$ \\
\hline Io & 71.025 & 595.25 & 42125 \\
\hline
\end{tabular}

This "reciprocating portion" of the balance weight, viz., $444 \mathrm{lbs}$. at 13 in. radius can be divided between the first and second driving wheels in the ratio of the static weights on the wheels. The result would be the reduction of the final swaying moment in a similar manner to that shown in Fig. I7, curve III. to curve V. As the balance weights in opposite wheels would be very nearly opposite to each other, only a slight surging force would be introduced. The critical speed with divided balance weights would be so high as not to require consideration. Moreover, it will be shown at the end of the paper that the actual swaying oscillation of a heavy engine is so small that the reciprocating masses may be neglected at all events in a four-cylinder engine.

\section{Complete Balancing of Four-Cylinder Engines without the Use of Balance Weights.}

This is possible with the Schlick system, but the cranks have to be set at different angles, so that four valve gears, one for each cylinder, would be necessary. This system has never yet been applied to any locomotives in this country, nor, as far as the author is aware, to any abroad.

In this system it is necessary to settle the weights of two sets of reciprocating parts, say, those for the outside cylinders, and also the crank angle between them, which for starting purposes may be fixed at $90^{\circ}$ as in an ordinary two-cylinder engine. Conditions of symmetry in a locomotive necessitate that these outside reciprocating masses must be equal.

* Planes Nos. $2,3,8$, and 9 have only revolving masses, not here considered. 
Fig. 22 shows the elevation with the outside cranks Nos. 1 and 2 at right angles, and Fig. 23 the plan. Suppose the total outside reciprocating masses to weigh 6oolbs., and to be $7 \mathrm{ft}$. apart centre to centre of cylinders, figures which are very slightly different from those of the L. and Y.R. 4-6-o engine. The inside cylinders are supposed to be $2 \mathrm{ft}$. apart. As we are now balancing one set of reciprocating masses by another set, the reference plane is taken in the plane of one of the inside sets, say, No. 4, from which is obtained the following schedule :-

$\begin{array}{cccc}\text { Distance from } & & \\ \text { Plane } & \begin{array}{c}\text { Reference } \\ \text { Plane. }\end{array} & \text { Masses. } & \text { Mass } \\ \text { No. } & \text { feet. } & \text { lbs. } & \text { lbs.-ft. } \\ 2 & -2.5 & 600 & -1500 \\ 4 & 0 & (1550) & 0 \\ 3 & 2 & (1550) & (3100) \\ \text { I } & 4.5 & 600 & 2700\end{array}$

The mass moment polygon is shown in Fig. 24 and the force polygon in Fig. 25. The inside reciprocating masses are each 1,55olbs. set at the crank angles shown in Fig. 22. With the exception of the "secondary" moments caused by the obliquity of the connecting rods, the whole of the forces and moments balance each other without the aid of any balance weights.

This result has been obtained at considerable expense in other directions. Apart from the extra valve gears an enormous reciprocating mass is required for the inside cylinders, which, for the given distances apart, must be 2.583 times that of the outside cylinders. The crank angles are such that the engine might not work satisfactorily. The Paris-Lyons and Mediterranean Railway made their early compound engines with the inside and outside cranks set at $135^{\circ}$ for the purpose of obtaining a better starting moment, but found difficulty in the balancing arrangements, and abandoned the practice in later designs.* But these engines were not balanced on the Schlick system.

Comparison of Different Types of Engines.

Table Appendix VI. shows the maximum unbalanced surging forces and swaying moments of two-, three- and four-cylinder engines. But as such formulæ are not convenient for showing by inspection the comparative values for

* Revue générale des Chemins de fer, Septembre, 1898 . 
the different types of engine, Table VII. has been prepared by working out an assumed concrete example.

\section{Effect of Slide Bar Pressures.}

Under normal circumstances no calculation need be made of these, more especially as they cannot be balanced. They may, however, assume importance in the case of an engine with a large unbalanced swaying moment, especially one with outside cylinders, for the reason that the rolling and pitching movements produced by the action of these pressures is superposed upon the swaying moments and external disturbances and may carry the total disturbances of the engine beyond safe limits. Fig. 26 shows a number of curves giving the slide bar pressures, which have been drawn by using indicator diagrams of the Midland threecylinder compound at 65 miles per hour (taken from " Engineering," February, I903), and correcting them for the inertia of the reciprocating parts, in order to obtain the resultant mean effective pressures $\left(P \pm p_{1}\right)$ throughout one revolution. Curves I. and II. are for the L.H. and R.H. outside cylinders respectively, and curve III. for the central inside cylinder. Curve $\mathrm{V}$. is the combined sum for all three cylinders, the pressure on the slide bars being upwards. This combined pressure reaches a maximum of $5,500 \mathrm{lbs}$. (2.45 tons) at the speed mentioned lifting the engine at the front end. In a four-cylinder engine the lifting force would be still greater.

Curve IV. shows the lifting force for two cylinders only and is the resultant of combining curves 1 . and II. The third cylinder produces no rolling motion as it is on the centre line of the engine, but the two outside cylinders, each $3 \mathrm{ft}$. $1 \frac{1}{2}$ in. from the centre of the engine, produce the rolling action shown in Fig. 27 (moments above the horizontal being clockwise, viewed from the footplate end). Both pressures being in general upwards, the rolling produced by the R.H. crosshead is in the opposite direction to that produced by the L.H. one and the maximum occurs when the R.H. crank is near $90^{\circ}$, when the value is $2,65^{\circ}$ $\times 3.125=8,281 \mathrm{lbs}$.-feet. In addition to the rolling the slide bar pressures produce a longitudinal galloping action, due to the pressure being accompanied by an equal downward thrust at the crank axle. The arm of the couple is the length between the centre of crosshead and centre of crank axle, a quantity constantly varying with the position of the crosshead. For instance, when the R.H. outside crank is 
at $120^{\circ}$ the ordinate of curve $V$. (three crossheads combined) is nearly $5,200 \mathrm{lbs}$. and the arm of the couple approximately $5 \mathrm{ft}$. $8 \mathrm{in}$., so that the longitudinal turning moment is approximately $29,47 \mathrm{olbs}$.-feet, tending to make the engine "gallop." This has to be resisted by the springs, hence, as previously explained, the advantages of plate springs of sufficient stiffness at the leading and trailing ends. The more the number of cylinders, the greater is the "galloping" action, but if the cylinders are near the centre of the engine, as in many foreign locomotives, the "galloping " action is imperceptible.

\section{Division of Balance Weights between Coupled Wheels.}

The weights counterbalancing the revolving masses must under no circumstances be divided between the wheels, but should be placed on the axle or in the rims of the wheels of the axle on which the masses to be balanced are revolving. It is obvious that the vertical component of a revolving balance weight would, if part of such weight were placed in another wheel, simply tend to lift that wheel against the spring or press it on the rails, and this component could not produce any effect on the engine itself unless in an extreme case it lifted the axlebox against the top of the horn blocks. Even if the frame at the trailing wheel were lifted it would not affect the driving axle, as there is the elastic cushion of the driving spring interposed.

The "reciprocating" balance weights may however be divided, as their effect is intended to be in a horizontal direction, and presses the axlebox of the wheel against the horns, and so translates the pressure to the engine.

Many engineers prefer not to divide even the reciprocating balance weights. This procedure may be possible in, say, an express engine with $6 \mathrm{ft}$. 6in. to $7 \mathrm{ft}$. wheels, where there is room for one large balance weight. In the case of the heavy eight wheels coupled passenger engines of the South African railways ( $3 \mathrm{ft}$. 6in. gauge) some of which have $4 \mathrm{ft}$. coupled wheels, and large 2 in. $\times 26 \mathrm{in}$. cylinders, the reciprocating masses are fully as heavy as those of the largest main line engines in this country. A $7 \mathrm{ft}$. wheel at 70 miles per hour makes 4.662 revs. or about 28.9 radians per second, and a $4 \mathrm{ft}$. wheel is revolving at the same angular velocity when the engine is travelling at 40 miles per hour. The balancing of these heavy narrow gauge engines is a matter of considerable difficulty. Large masses acting at smaller radii have to be introduced, and 
it is essential in many of these engines to divide the reciprocating balance weights between four pairs of wheels.

Effect of Obliquity of Connecting Rod.

In the first calculations for balancing the reciprocating masses it is useless to take this effect into consideration. The secondary forces and moments produced by this obliquity cannot be balanced by revolving weights. If we make the balance weight $\frac{x}{n}$ th greater to allow for the obliquity at the front end, it will be $\frac{2}{n}$ ths too great at the back end of the stroke, where the balancing mass should theoretically be $\frac{I}{n}$ th less. Moreover, in adopting an approximate convention of balancing only one-half, twothirds, or other empirical fraction of the reciprocating masses, it is waste of time quibbling over the obliquity effect.

It is worth while noting that the surging forces in a two-cylinder engine with cranks at $90^{\circ}$, or in a four-cylinder engine with cranks at $180^{\circ}$, are not affected by the variations due to the obliquity, as these variations balance each other, but the swaying moments are considerably increased. In the Midland engine, considered in the earlier part of this paper, the value of $\left(\operatorname{Cos} \theta+\frac{\operatorname{Cos} 2 \theta}{n}\right)$ is 1.15 at the front end, and .85 at the back end, a $15 \%$ increase for each cylinder at the front, and a $5 \%$ decrease at the back.

After the balance weights have been approximately settled the swaying moments should be calculated with the obliquity effect included, for the result of this calculation may necessitate some alteration of the balance weights, though the balance weights themselves cannot alter the obliquity effect.

\section{Balance Weights in Extension of Crank Arms.}

Such balance weights are becoming more usual. They have the advantage of relieving the crank axle of severe bending stresses, but a consideration of this point would involve the whole question of the strength of axles, which is beyond the scope of this paper. 


\section{"Hammer" Effect. Variation of Rail Load.}

This has already been mentioned and will come under further consideration at the end of the paper. The author here merely draws attention to a possible source of danger in the Stroudley method of balancing. He once noticed in the north of England an engine which had been constructed by a private firm for one of the southern lines, on its way south as a "dead engine" in an express goods train, which was at the time running at fully 35 to 40 miles per hour. The engine was balanced on the Stroudley system and the connecting and coupling rods had been removed. The vibration of the dead engine was distinctly noticeable. The author has worked out the case of an engine, which when balanced in the usual manner has a total balance weight of 494lbs. at 13 in. radius. When the inside and outside rods are removed, there remain only the disturbing forces due to the revolving inside crank webs and pin, and the outside unbalanced bosses and pins. The portion of the balance weight required to fully balance these is 305 lbs., so that there would remain in the driving wheels, r8glbs. revolving balance weight causing "hammer effect," swaying and rolling. At 35 miles per hour, with a $5 \mathrm{ft}$. wheel, the variation in rail load would be only $\pm \mathbf{x . 2}$ tons.

If on the other hand this engine were balanced on the Stroudley principle with inside and outside cranks on the same side of the axle, the total balance weight would be $1,08_{3}$ lbs., of which 394 lbs. would balance the revolving webs, boss and crank pins. The remainder, 68glbs. in the driving wheel, would cause a variation of rail load of \pm 4.37 tons. As the engine is " empty," the load on one driving wheel would be reduced at each revolution at 35 m.p.h. to $7.05-4.37=2.68$ tons, and this would probably be reduced still further if the rolling of the engine on the springs synchronised with this minimum value in such a way as to lift the engine on that side when the balance weight is at the top.

For this reason "dead engines" balanced on Stroudley's principle should preferably be run in slow goods trains not exceeding a certain speed.

\section{Division of the Connecting Rod into Revolving and Recipro- cating Portions.}

It has been usual to assume a fraction of the connecting rod to revolve, say, two-thirds or three-fifths. This approximate assumption may be far from correct, though 
the error is of minor importance, insofar as the reciprocating portion only is concerned, because if we assume the amount of the reciprocating masses to be balanced, the exact value of such assumed portion is not worth troubling about. But it is important to have the revolving portion as nearly as possible correct, for the revolving masses should be balanced as nearly accurately as possible.

Prof. Dalby gives the following rule for dividing the connecting rod:-

$a=$ crosshead to centre of gravity of the rod.

$b=$ crosshead to centre of percussion (or centre of oscillation) of the rod.

$l=$ length of the rod.

$M=$ mass of the rod.

The best distribution is effected when the mass considered as revolving at the crank pin is. $M \frac{a b}{l^{2}}$, and the remainder reciprocates with the crosshead.

Attention has been drawn to this specially to show how large the difference between the proper and usually estimated amounts may be. Mr. G. Hughes (Proc. Inst. Mech. Engrs., 1909) has calculated the proportions of his connecting rods in accordance with Prof. Dalby's expression, with the following results:-

Total

Weight. lbs.

Inside Rod ... ... 433

Outside Rod $\quad \ldots \quad 438.75$
Revolving Reciprocating Portion. Portion. lbs.

$25^{2.2}$

187 lbs.

180.8

Had these rods been calculated by the rough and ready method, two-thirds revolving and one-third reciprocating, the false results would have been :-

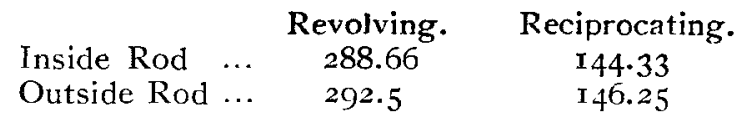

The great differences in the amounts of the revolving portions by the two methods will be noted.

Engines of the Double Steam Bogie Type.

This includes all engines in which two steam bogies are used, such as in the Fairlie, Meyer and Garratt systems.

The resistance to the unbalanced swaying motion of an 
ordinary engine of standard type is due to the inertia of the mass on the journals of the engine, including the boiler and main frames, because any tendency to oscillate the engine is immediately communicated from the axleboxes to the whole of the superposed mass. In the case of engines of the steam bogie type, only the weights of the cylinders, motion, and bogie frame can come into action to resist the swaying, for the boiler or any part resting on the bogie does not move with the bogie but slides or swings more or less freely, unless the amplitude of the movement is sufficient to fully compress the check springs. There is therefore in the case of these engines a much smaller inertia resistance, and consequently the actual amount of side sway is much greater, so much so that the real point of resistance frequently becomes that where the flange of the tyre presses against the rail. For these reasons as much of the reciprocating masses as possible should be balanced and the speed of such engines rigidly restricted.

The double bogie 4-4-2 Garratt passenger engines for Tasmania, with $5 \mathrm{ft}$. driving wheels, have four cylinders, Izin. by zoin., to $t a c h$ bogie, and it appears to the author that this arrangement may have been specially adopted for the sake of ol:taining a better " reciprocating" balance. The double 2-6-2 Garratt goods engines built for Tasmania at the same time have only two cylinders, I 5 in. by $22 \mathrm{in}$., to each bogie, owing probably to the slower speeds at which they are to run. These have $3 \mathrm{ft}$. $6 \mathrm{in}$. wheels.

\section{Amount of Sway. Effect of the Mass and Length of the Engine.}

So far no mention has been made of the important influence of the weight of the engine resting upon the journals, ${ }^{*}$ and also of the length of the engine, in resisting the swaying moment.

The problem is to find what portion of the reciprocating masses should be balanced in order that

(1) The horizontal swaying oscillation at the extreme axles (or bogie pin), and

(2) The variation of rail pressure should not exceed certain limits.

$W_{\mathrm{o}}$ lbs. = unbalanced portion of reciprocating masses.

* The weight in question is that of the oscillating portion of the engine. 
2 c feet $=$ distance from centre to centre of cylinders, so that $c$ is the distance of the line of action of the swaying force $F$ from the axis of rotation of the body of the engine.

$r$ feet $=$ crank radius.

$T$ lbs. = oscillating weight of the engine on the journals and on bogie plate (if a bogie engine with side movement of bogie pin).

$L$ feet $=$ radius of gyration of the oscillating mass.

$\mathrm{s}$ feet $=$ semi-amplitude of oscillation (i.e., on each side of centre line of engine) at a distance of one foot from the C.G.

$m$ feet $=$ distance of leading axle or bogie pin from the C.G. of engine.

$$
s=\frac{1.4 \mathrm{I} 4 W_{0} c r}{T L^{2}}
$$

(See Appendix VIII., which shows how equation (a) has been obtained.)

The semi-amplitude of oscillation at the leading axle or bogie pin $=m s$ feet $=12 \mathrm{~ms}$ inches

$$
=\frac{17 W_{0} \mathrm{crm}}{T L^{2}} \text { inches nearly. }
$$

(In using formula $\left(a_{1}\right)$ note that $c r m$ and $L^{2}$ are all expressed in foot units and that only the coefficient has been altered.)

The value of $L$, the radius of gyration, can be derived with exactitude by means of a long and tedious calculation. This has been made in the case of certain foreign locomotives. Monsieur Maréchal, the Chief of the Matériel and Traction Dept. of the P.L.M. Railway of France, has very kindly pointed out to the author that they have found from long experience of all classes of engines that

$$
L^{2}=\frac{T_{1}}{7^{19^{2}}} \text { in metre and kilogramme units }
$$

(a formula due to the late Monsieur Le Chatelier). In British units this becomes

$$
L^{2}=\frac{T}{\mathrm{I}_{47^{2}}}
$$

in which $T$ is in lbs. and $L^{2}$ in foot units.

If $T$ be expressed in tons $\left(T_{0}\right)$

$$
L^{2}=1.522 T_{0}
$$

The amount of swaying oscillation in inches on each 
side of the centre line will be (from equation $\left(a_{1}\right)$ in which the value of $L^{2}$ from $\left(b_{1}\right)$ has been substituted)

$$
\frac{25024 W_{0} \mathrm{crm}}{T^{2}}
$$

It is simpler to express $T$ in tons than in lbs. in which case the oscillation on each side in inches

$$
=\frac{.005 W_{\mathrm{o}} \mathrm{crm}}{T_{\mathrm{o}}^{2}}
$$
engine.

Note that this value is independent of the speed of the

As an example, suppose the 4-4-o outside cylinder engine considered earlier in this paper, of which the weight on the journals will be about 48.2 tons. If the reciprocating masses are entirely unbalanced $\left(W_{0}=7\right.$ rolbs., $c=\frac{25}{8}$ ft., $r=\frac{13}{12} \mathrm{ft}$., and $m=10.5 \mathrm{ft}$.), from equation $\left(c_{2}\right)$ the oscillation on each side of the centre line will be .0554 inch, or about $\frac{3 \frac{1}{2}}{64}$ inch. If two-thirds of $W_{0}$ are balanced the oscillation will be reduced to one-third of $.0554=.0185$ inch. The effect of a long and heavy engine is clearly seen, as the oscillation varies inversely as the square of the weight of the engine. A shorter and lighter engine will oscillate more, and would therefore require to have a larger proportion of the reciprocating masses balanced than the heavy engine.

In an engine with a leading bogie, the swaying oscillation at the leading end will be largely taken up by the check springs at the bogie pins. But at the trailing axle the conditions are similar to those in an engine with one leading axle. If the total swaying oscillation exceeds the total amount of side play between horn blocks and axleboxes, and between collars and brasses combined, a hammering will occur on the horn blocks tending to bend the frames. It is possible that some broken frames may be due to this action. In the case of the above engine, the oscillation at the bogie pin or trailing axle, when no reciprocating masses are balanced is less that $x / 16$ inch each side, and this might be allowed for in the side play.

The best balance for a heavy engine, therefore, appears to resolve itself into one for the maximum variation of rail 
pressure allowed, at the maximum speed at which the engine travels. It must not be forgotten that the modern English express engine occasionally reaches 70 miles per hour, and speeds of nearly too m.p.h. have-though very rarelybeen attained.

The conditions as to rail pressure are by no means fixed in this country, but in Belgium, Germany and Sweden the maximum must not be more than I 5 per cent. above the static load on the driving wheel, though in this country the maximum is a much higher percentage in most cases.

If $P$ be this static load in tons $P(\mathbf{r}+y)$ is the maximum permissible rail load in tons (for 15 per cent. $y=.15$ ).

$V$ miles per hour $=$ speed.

$W_{\mathrm{b}}$ lbs. = balance weight at crank radius (for reciprocating masses only).

$D$ feet $=$ diameter of driving wheels.

$\frac{W_{\mathrm{b}} \omega^{2} r}{g}=y P \times 2240$.

$\therefore W_{\mathrm{b}}=\frac{y P g}{\omega^{2} r} \times 2240$ for maximum value of $W_{\mathrm{b}}$

Since $\omega=\frac{44}{15} \frac{V}{D}$ radians per sec. and $g=\mathbf{3 2 . 2}$.

$\mathbf{W}_{\mathrm{b}}=\frac{8_{3}^{8}{ }^{8} y P D^{2}}{V^{2} r}$

If $V$ be the maximum speed, $W_{\mathrm{b}}$ will be the maximum amount of reciprocating balance weight, such that the variation of rail pressure does not exceed $y$ per cent. more or less than the static load on the driving wheels.

$$
\begin{aligned}
& \text { If } V=90 \text { miles per hour, } D=7 \mathrm{ft} ., r=\frac{13}{12} \mathrm{ft} \text {. } \\
& P=9.5 \text { tons, } y=.15 \text {. }
\end{aligned}
$$

From equation $(d) W_{\mathrm{b}}$ will be 66.7 lbs. at crank radius.

The proportion of the reciprocating masses balanced by this weight may be found from the data in the earlier portion of the paper. If the engine has outside cylinders the balance weight will be greater than the amount of the reciprocating weight. which it balances. For instance, this engine required $538 \mathrm{lbs}$. balance weight for a reciprocating mass of two-thirds of 7 rolbs. $\left(=473.3^{\mathrm{Ibs}}\right)$ and the ratio of

$\frac{\text { balance weight }}{\text { reciprocating mass balanced }}$
for this particular engine. 
The proportion of the reciprocating masses balanced is therefore $\frac{66.7}{1.14} \times \frac{100}{710}=8 \frac{1}{4}$ per cent.

For an inside cylinder engine the balance weight is less than the weight of the reciprocating mass which it balances. The engine considered previously required $332 \mathrm{lbs}$. balance weight for two-thirds of $650\left(=433^{\mathrm{lbs}}\right.$.) reciprocating mass and the ratio $=\frac{33^{2}}{433}=0.76$.

The proportion of reciprocating masses balanced is therefore $\frac{66.7}{.76} \times \frac{100}{650}=13 \frac{1}{2} \%$.

The oscillation of the outside cylinder engine will be $91 \frac{3}{4}$ per cent. of .055 in. $=.05$ in., and of the inside cylinder engine about $86 \frac{3}{4}$ per cent. of .0185 in. $=.0 .16$ in.

The above assumes that the balance weights are in one pair of wheels only. We may, however, add another $67 \mathrm{lbs}$. in the trailing wheel,* or if the engine be a six-coupled one, place 67 lbs. in each wheel.* In this case we balance double or treble the percentages given above, and improve the stability. The four-coupled outside cylinder engine would have $16 \frac{2}{2} \%$ balanced and the oscillation reduced to about .025 in., and the inside cylinder engine would be balanced to the extent of nearly 27 per cent., with an oscillation of only about .oosin.

Apart from the advantage to the permanent way and bridges, the locomotive itself is the gainer by keeping $y$ as small as possible, for the value $P(x-y)$ determines the frictional resistance at the rail, and consequently the limit at which the driving wheel slips.

The conclusion drawn by the author is that in this country with modern heavy engines too great a proportion of the reciprocating masses is balanced. In certain cases the wheels will actually lift at speeds of $8 \mathrm{I}$ to 90 miles per hour. At 70 miles per hour the four-coupled outside cylinder engine, taken as an example, has a variation of rail load of $62 \frac{1}{2}$ per cent. with two-thirds of the reciprocating masses balanced. It would seem that this proportion of twothirds was decided when engines were much smaller and lighter than they are now, and that it has been handed down from a former generation of locomotive designers. The

* Supposing the load on each wheel is 9.5 tons. 
conditions are now very different. Other things being equal, the swaying moment varies as the weight of the reciprocating masses, and if we take a 2-4-o engine of about 30 to 40 years ago, these masses would weigh, say, 55olbs. per cylinder. In the modern engine they have increased to, say, 65olbs. This increase is about $18 \frac{1}{4}$ per cent. The resistance to swaying oscillation is $T L^{2}$. In the old engine, of which the total weight was 35 to 36 tons, $T$ would be about 29 tons, and $L$ about $7 \mathrm{ft}$, , so that the value of $T L^{2}$ would be $\mathrm{I}, 42 \mathrm{I}$. In the large 4-4-0 engine $T$ is, say, 49 tons, and $L=$ about 8.2ft., so that $T L^{2}=3,283$, an increase of ${ }^{1} 3^{I}$ per cent. of resisting moment, as against an increase of oscillating moment of only $18 x$ per cent. This goes to prove that a smaller proportion than two-thirds could be balanced. These remarks do not apply to a fourcylinder engine of the Lancashire and Yorkshire type in which there are no balance weights for reciprocating masses.

Moreover, the above investigations have treated the question throughout as if the driving wheels rolled steadily on the rails, and that the variation of rail load would therefore follow a curve of sines. The rolling of the engine on the springs may considerably modify the values of the expression for the rail load, which would then become $P(\mathrm{r} \pm y) \pm Q_{2} Q$ being a force due to rolling, the calculation of which is very complicated. If $Q$ is positive, an additional load is thrown on to rails and bridges, and if $Q$ is negative at the same instant that $y$ is also negative, the driving wheel might easily lift sooner than has been previously calculated and bring the critical speed down to 70 to 75 miles per hour. This would be a dangerous condition for a modern express engine.

\section{FOREIGN PRACTICE.}

France (Ch. de fer du Nord).

Monsieur Asselin, the Chef du Matériel et de la Traction, has kindly given the author the following note:-

" In our four-cylinder engines the revolving masses only are balanced. The cranks on each side of the engine being at $180^{\circ}$, the reciprocating masses balance each other to a sufficient degree, which is the more nearly correct as our small cylinders are always outside and our large cylinders inside, so that their corresponding swaying moments are only slightly different in value. 
"The above method has the advantage of producing no hammer blow effect on the rails."

The author is also indebted to Monsieur Asselin for the following weights of connecting and coupling rods, which are good examples of light section rods used in the de Glehn compounds. The type of engine is the Nord 4-6-0, H.P. cylinders (outside) I 5 in. by 25 tin., L.P. cylinders (inside) 21 in. by 25 tin., boiler pressure 227.5lbs. per sq. inch, high pressure steam up to $85 \mathrm{lbs}$. per sq. inch admitted to the L.P. cylinders.

Total Weights of Rods including brasses.

\section{Length,}

Centre to Centre. Weight.

H.P. connecting rod (outside) ... 6ft. 2.8in. 286.5lbs. L.P. connecting rod (inside) $\ldots$ 5ft. ro.gin. 330.6lbs. Coupling rod (leading portion) ... $6 \mathrm{ft}$. $2.8 \mathrm{in}$. 224.8lbs. Coupling rod (trailing portion) ... 7 ft. 101in. 359.2lbs.

\section{France (Paris, Lyons and Mediterranean Railway).}

M. Maréchal, Chief of the Locomotive Dept., writes that for four-cylinder engines they do not trouble to balance the reciprocating parts, which he considers are sufficiently well balanced amongst themselves, as their total effect is not any more dangerous than the action of the reciprocating Darts-only partially balanced-of a two-cylinder engine. Generally speaking, they do not impose a fixed limit upon the variation of load upon the driving wheels, but content themselves by completely balancing the revolving masses.

\section{Belgian States Railways.}

The following information was kindly supplied by Monsieur J. B. Flamme :-

" In our engines with four equal cylinders, whether connected to one or to two driving axles, we do not counterbalance the reciprocating masses. The counterweights in the wheels balance the revolving masses exactly. In our engines type 8 (four-cylinder de Glehn type compounds) we balance half the difference between the outside and the inside reciprocating parts. 
The following are the weights of the reciprocating masses of the Belgian four-cylinder engines:-

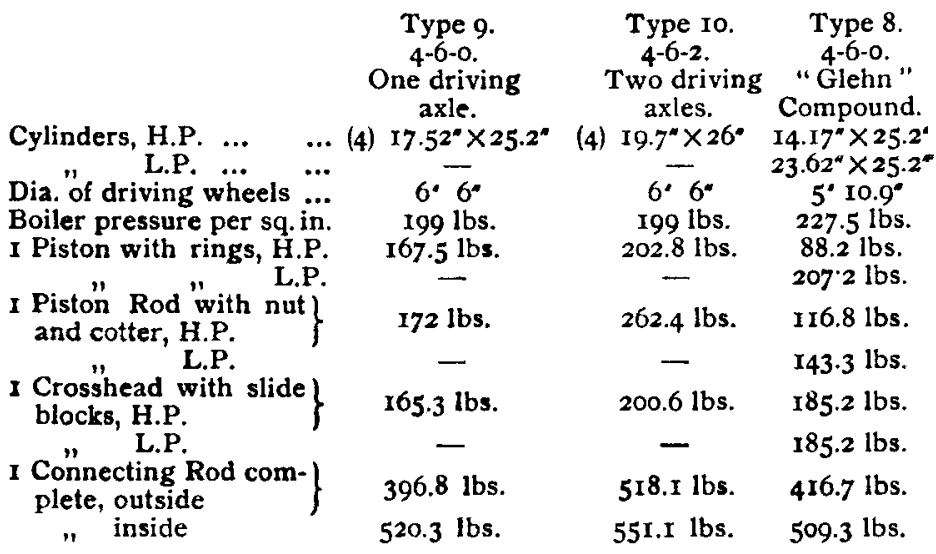

In Belgium the reciprocating masses of two-cylinder engines are balanced only to such an extent that the vertical component of the balance weight does not exert an extra pressure on the rails exceeding 15 per cent. of the static load.

\section{Germany.}

The weight and length of the engine exercise considerable influence in deciding the proportion of the reciprocating masses to be balanced. For instance, some of the older and smaller 2-4-o passenger engines have 50 per cent. balanced, whilst some of the 4-4-o have only some 16 per cent. balanced.

In some of the Austrian 4-4-0 and 4-6-0 engines only ro per cent. of the reciprocating masses is balanced.

In Germany it is compulsory for all new engines not to exceed a rail pressure of $r_{5}$ per cent. higher than the static load on the driving wheels, at the maximum speed.

\section{Sweden.}

In the recently built 4-6-o express engines with two cylinders, 7 per cent. of the reciprocating masses is balanced in each coupled wheel-2 $\mathrm{I}$ per cent. in all. This allows of a variation in wheel pressure on the rails of 15 per cent. above and 15 per cent. below the static weight on the wheels, at a speed of $5^{6}$ miles per hour. The connecting rods are divided in the proportion of $3 / 5$ revolving and $2 / 5$ 
reciprocating, and the eccentrics and eccentric rods are included. In the latest 4-6-2 four-cylinder engines, which have only just been built, the reciprocating masses have not been balanced by means of counter-weights, in order to avoid variation of rail pressure.

\section{American Practice.}

The empirical rule adopted by the American Master Mechanics' Association is to allow $1 / 400$ th part of the weight of the engine to remain unbalanced in the reciprocating parts. This is generally modified by limiting the balance to between 55 per cent. and 65 per cent. of the weights of the reciprocating parts, and dividing this between the coupled wheels. In the case of engines with small wheels, such as eight-coupled freight engines, if there is not room in the driving wheel for the whole of this wheel's portion of the weight, the excess is only put in the other wheels if it is less than $\frac{.65 \text { reciprocating weight }}{\text { number of axles. }}$

If there still remains a deficiency, the speed limit of the engine is reduced.

\section{Breda's Engine.}

An interesting four-cylinder balanced engine was proposed and designed by the Soc. Italiana Ernesto Breda, of Milan, for the Italian Government railways. This was a 2-10-2 tank engine for banking passenger and goods trains. The H.P. cylinders were to be at the footplate end, and the L.P. cylinders in the usual position by the smoke-box. The arrangement is shown in Fig. 28, from which it will be seen that not only do the reciprocating masses balance, but that the secondary moments caused by the obliquity of the connecting rods cancel one another. Each wheel has its own revolving masses balanced by a counter-weight in the usual manner.

This remarkable engine was not constructed, as the railway administration preferred a 0-10-o type of their own design with four cylinders in line at the smoke-box end.

In conclusion, the author begs to thank Mr. Henry Fowler, Chief Mechanical Engineer of the Midland Railway and Past President of this Institution; Mr. George Hughes, Chief Mechanical Engineer of the Lancashire and Yorkshire Railway; and Mr. A. C. Stamer, Chief Assistant Mechanical 
Engineer of the North-Eastern Railway, for information kindly placed at his disposal. Thanks are also due to $\mathrm{Mr}$. J. B. Flamme, late Chief Locomotive Engineer of the Belgian States Railways, and to Mr. Asselm, Chief of the Northern of France Railway, for particulars as to their practice.

The author also wishes to acknowledge the use he has made of Professor Dalby's graphical method of finding the balance weights, full particulars of which will be found in the Inst. Mech. Engineers, I90I.

$\mathrm{He}$ has also to acknowledge with many thanks the generous assistance given by Professor Bulleid, M.A., Head of the Engineering Department of University College, Nottingham, who kindly read through the paper, and suggested one or two additions and corrections in the figures.

The paper has entailed a large amount of calculations, and should there be any errors which have slipped through, the author hopes that they will be pointed out and excused. 


\section{APPENDIX-TABLE I.}

Three-Cylinder High Pressure Locomotives.

\begin{tabular}{|c|c|c|c|c|c|}
\hline Name of Railway. & Class of Engine. & Outside Cylinders. & $\begin{array}{c}\text { One } \\
\text { Inside Cylinder. }\end{array}$ & $\begin{array}{l}\text { Dia. of } \\
\text { Driving } \\
\text { Wheels. }\end{array}$ & $\begin{array}{l}\text { Number } \\
\text { of } \\
\text { Engines. }\end{array}$ \\
\hline $\begin{array}{ccc}\text { Great } & \text { Central } & \ldots \\
\text { North } & \text { Eastern } & \ldots \\
", & ", & \ldots \\
", & " & \ldots \\
", & " & \ldots \\
\text { Great Eastern } & \ldots\end{array}$ & 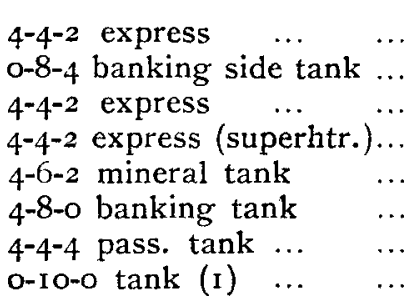 & 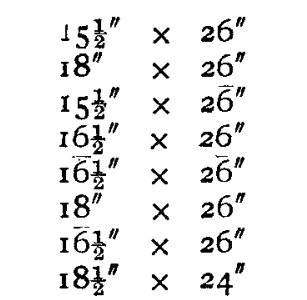 & $\begin{array}{lll}15 \frac{1}{2} & \times & 26^{\prime \prime} \\
18^{\prime \prime} & \times & 26^{\prime \prime} \\
15 \frac{1}{2} & \times & 26^{\prime \prime} \\
16 \frac{1}{2} & \times & 26^{\prime \prime} \\
16 \frac{1}{2} & \times & 26^{\prime \prime} \\
18^{\prime \prime} & \times & 26^{\prime \prime} \\
16 \frac{1}{2}^{\prime \prime} & \times & 26^{\prime \prime} \\
18 \frac{1}{2}^{\prime \prime} & \times & 24^{\prime \prime}\end{array}$ & 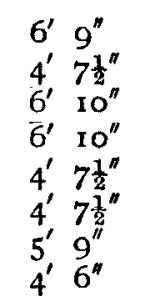 & $\begin{array}{r}\text { I }(b) \\
4 \\
\text { 10 }(a) \\
\text { 10 }(a) \\
20(a) \\
10(b) \\
20(a) \\
\text { I }(b)\end{array}$ \\
\hline
\end{tabular}

(a) All three cylinders connected to one driving axle.

(b) Outside and inside cylinders connected to separate axles.

(I) The Great Eastern engine was subsequently converted into a tender engine with two cylinders and eight coupled wheels. This has recently been broken up. 
APPENDIX-TABLE II.

Three-Cylinder Compound Locomotives.

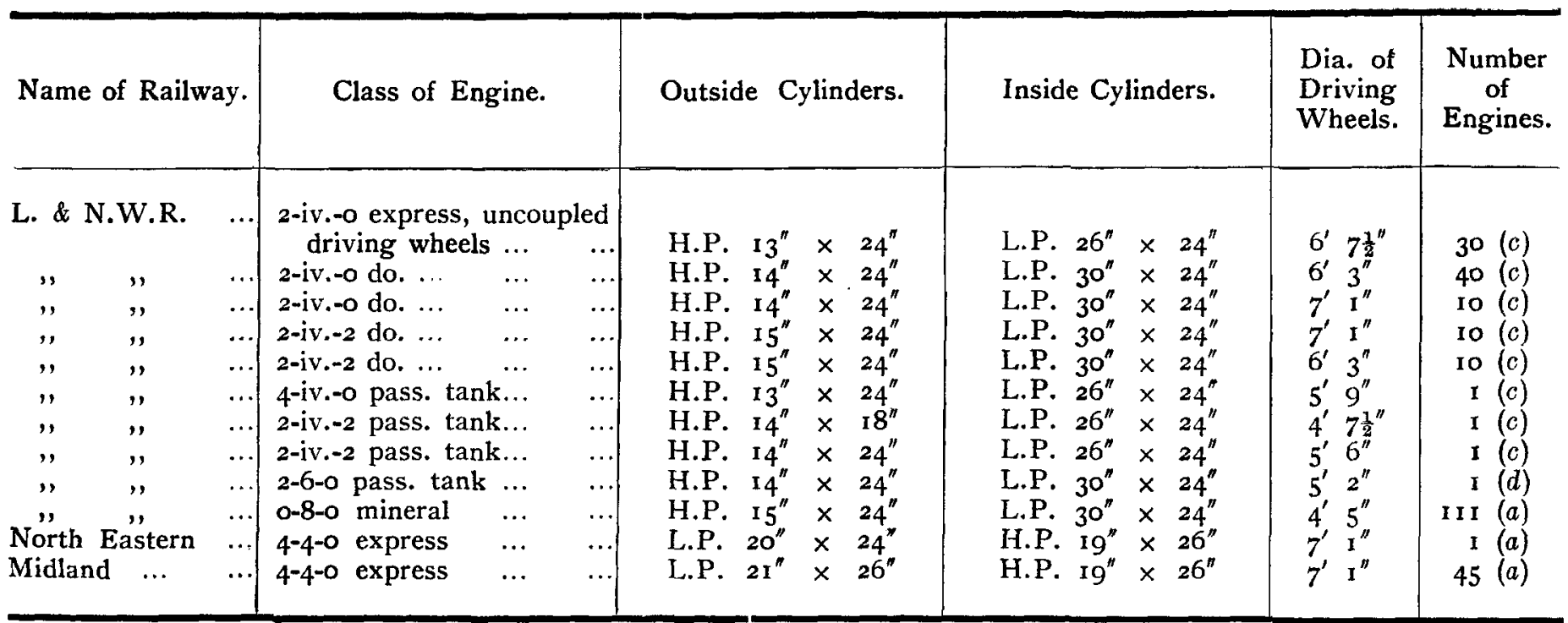

(a) The three cylinders connected to same driving axle.

(c) The L.P. inside cylinder connected to front driving wheels, and the H.P. outside cylinders to back driving wheels, which were uncoupled, except that in engine $(d)$ the back driving wheels were coupled to a trailing pair behind them. All these engines are obsolete and have been broken up. (Webb's original system.) 


\section{APPENDIX-TABLE III.}

\section{Four-Cylinder High Pressure Engines.}

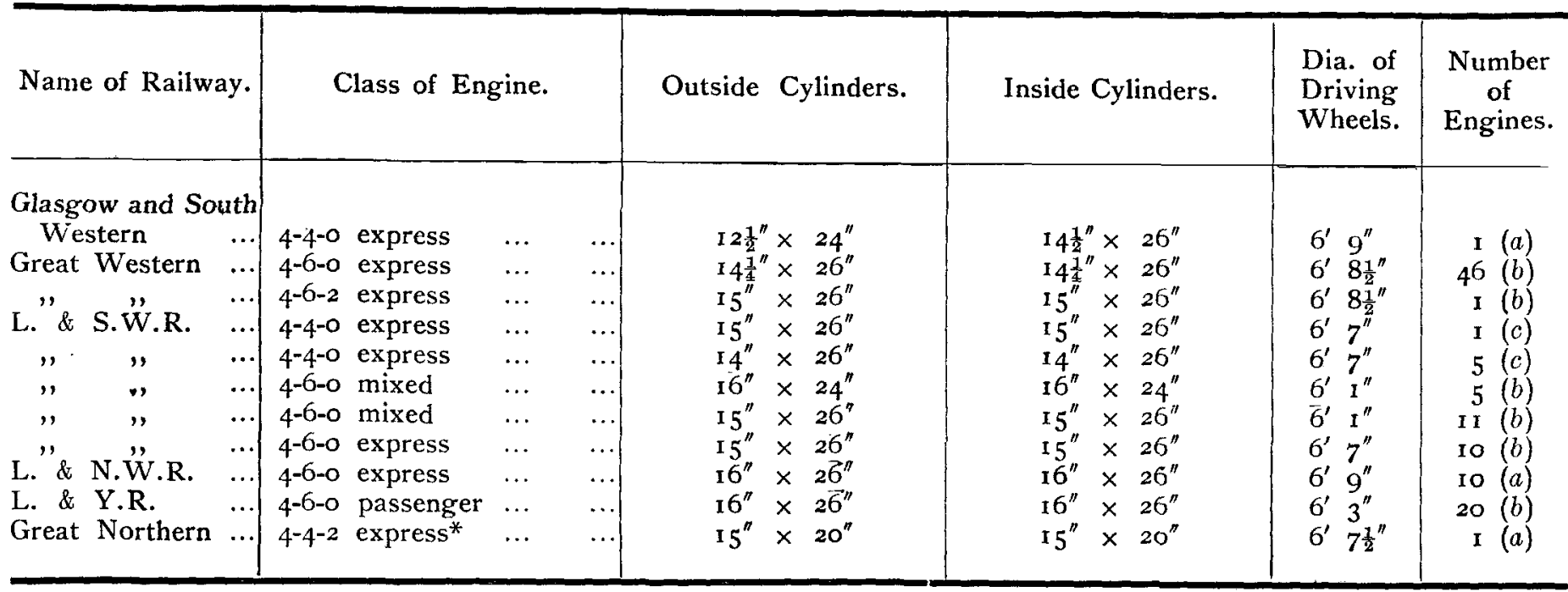

* This engine, after running for a few years, was subsequently converted to an ordinary two-cylinder engine with $18 \frac{1}{2}^{\prime \prime} \times 26^{\prime \prime}$ cylinders.

(a) All four cylinders connected to one driving axle.

(b) Inside and outside cylinders connected to separate driving axles.

(c) These engines have separate uncoupled driving axles. 
APPENDIX-TABLE IV.

Four-Cylinder Compound Engines.

\begin{tabular}{|c|c|c|c|c|c|c|c|c|}
\hline Name of Railway. & & Class of $\mathrm{E}$ & gine. & & Outside Cylinders. & Inside Cylinders. & $\begin{array}{l}\text { Dia. of } \\
\text { Driving } \\
\text { Wheels }\end{array}$ & $\begin{array}{c}\text { Number } \\
\text { of } \\
\text { Engines. }\end{array}$ \\
\hline 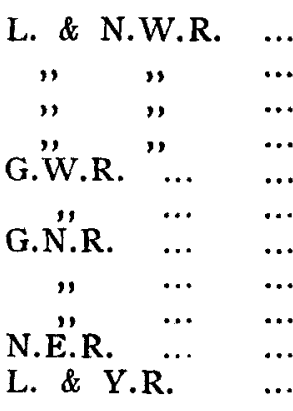 & $\begin{array}{l}4-4-c \\
4-4-c \\
4-6-c \\
0-8-c \\
4-4-2 \\
4-4-2 \\
4-4-2 \\
4-4-2 \\
4-4-2 \\
4-4-2 \\
0-8-c\end{array}$ & $\begin{array}{l}\text { express } \\
\text { express } \\
\text { goods } \\
\text { and } 2-8- \\
\text { express } \\
\text { express } \\
\text { express } \\
\text { express } \\
\text { express } \\
\text { express } \\
\text { mineral }\end{array}$ & $\begin{array}{l}\ldots \\
\ldots \\
\ldots \\
\text { mineral } \\
\ldots \\
\ldots \\
\ldots \\
\ldots \\
\ldots \\
\ldots \\
\ldots\end{array}$ & \begin{tabular}{l|}
$\cdots$ \\
$\cdots$ \\
$\cdots$ \\
$\cdots$ \\
$\cdots$ \\
$\cdots$ \\
$\cdots$ \\
$\cdots$ \\
$\cdots$ \\
$\cdots$ \\
$\cdots$
\end{tabular} & $\begin{array}{l}\text { H.P. } 15^{\prime \prime} \times 24^{\prime \prime} \\
\text { H.P. } 16^{\prime \prime} \times 24^{\prime \prime} \\
\text { H.P. } 16^{\prime \prime} \times 24^{\prime \prime} \\
\text { H.P. } 16^{\prime \prime} \times 24^{\prime \prime} \\
\text { H.P. } 13 \frac{3}{8} \times^{\prime \prime} \times 25^{3} / 16^{\prime \prime} \\
\text { H.P. } 14^{3} /_{16}^{\prime \prime} \times 25^{3} / 16 \\
\text { H.P. } 13^{\prime \prime} \times 10^{\prime \prime} \\
\text { H.P. } 14^{\prime \prime} \times 26^{\prime \prime} \\
\text { H.P. } 13^{\prime \prime} \times 20^{\prime \prime} \\
\text { H.P. } 14^{\prime \prime} \times \times 26^{\prime \prime} \\
\text { H.P. } 15 \frac{1}{2} \times 26^{\prime \prime}\end{array}$ & 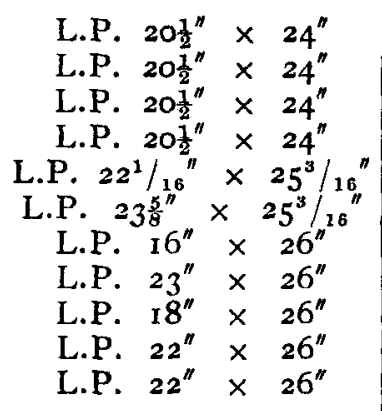 & $\begin{array}{ll}7^{\prime} & 1^{\prime \prime} \\
7^{\prime} & 1^{\prime \prime} \\
5^{\prime} & 3^{\prime \prime} \\
4^{\prime} & 5^{\prime \prime} \\
6^{\prime} & 8^{\prime \prime} \\
6^{\prime} & 8^{\prime \prime} \\
6^{\prime} & 8^{\prime \prime} \\
6^{\prime} & 8^{\prime \prime} \\
6^{\prime} & 8^{\prime \prime} \\
7^{\prime} & 1^{\prime \prime} \\
4^{\prime} & 6^{\prime \prime}\end{array}$ & $\begin{aligned} 40 & (a) \\
40 & (a) \\
30 & (a) \\
180 & (a) \\
1 & (b) \\
2 & (b) \\
1 & (b) \\
1 & (b) \\
1 & (b) \\
2 & (a) \\
11 & (b)\end{aligned}$ \\
\hline
\end{tabular}

(a) All four cylinders connected to one driving axle.

(b) Inside and outside cylinders connected to separate driving axles.

Note.-The four-cylinder compound L. \& N.W.R. engines are being gradually converted to two-cylinder simple engines with inside cylinders. 
Suraing Forces in Four-Cylinder Engine.

\begin{tabular}{|c|c|c|c|c|c|}
\hline 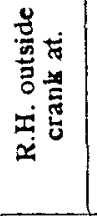 & $\begin{array}{c}\text { R.H. } \\
\text { outside. } \\
\text { lbs. }\end{array}$ & $\begin{array}{c}\text { L.H. } \\
\text { outside (at } \\
270^{\circ} \text { when } \\
\text { R.H. out- } \\
\text { side at } 0^{\circ} \text { ). } \\
\text { lbs. }\end{array}$ & $\begin{array}{c}\text { L.H. } \\
\text { inside (at } \\
90^{\circ} \text { when } \\
\text { R.H. out- } \\
\left.\text { side at } 0^{\circ}\right) \text {. } \\
\text { lbs. }\end{array}$ & $\begin{array}{c}\text { R.H. } \\
\text { inside (at } \\
\text { I80 when } \\
\text { R.H. out- } \\
\text { side at o } 0^{\circ} \text {. } \\
\text { lbs. }\end{array}$ & $\begin{array}{c}\text { Total } \\
\text { surging } \\
\text { force } \\
\text { for four } \\
\text { cylinders. } \\
\text { lbs. } \\
\end{array}$ \\
\hline $\begin{array}{c}0^{\circ} \\
15^{\circ} \\
30^{\circ} \\
45^{\circ} \\
60^{\circ} \\
75^{\circ} \\
90^{\circ} \\
105^{\circ} \\
120^{\circ} \\
135^{\circ} \\
150^{\circ} \\
165^{\circ} \\
180^{\circ} \\
195^{\circ} \\
210^{\circ} \\
225^{\circ} \\
240^{\circ} \\
255^{\circ} \\
270^{\circ} \\
285^{\circ} \\
300^{\circ} \\
315^{\circ} \\
330^{\circ} \\
345^{\circ} \\
360^{\circ} \\
=0^{\circ}\end{array}$ & $\begin{array}{l}\text { F. } 21575 \\
\text { F. } 20605 \\
\text { F. } 17655 \\
\text { F. } 13265 \\
\text { F. } 7975 \\
\text { F. } 2383 \\
\text { B. } 2815 \\
\text { B. } 7335 \\
\text { B. } 10785 \\
\text { B. } 13265 \\
\text { B. } 14840 \\
\text { B. } 15640 \\
\text { B. } 15945 \\
\text { B. } 15640 \\
\text { B. } 14840 \\
\text { B. } 13265 \\
\text { B. } 10785 \\
\text { B. } 7335 \\
\text { B. } 2815 \\
\text { F. } 2383 \\
\text { F. } 7975 \\
\text { F. } 13265 \\
\text { F. } 17655 \\
\text { F. } 20605 \\
\text { F. } 21575\end{array}$ & $\begin{array}{l}\text { B. } 2815 \\
\text { F. } 2383 \\
\text { F. } 7975 \\
\text { F. } 13265 \\
\text { F. } 17655 \\
\text { F. } 20605 \\
\text { F. } 21575 \\
\text { F. } 20605 \\
\text { F. } 17655 \\
\text { F. } 13265 \\
\text { F. } 7975 \\
\text { F. } 2383 \\
\text { B. } 2815 \\
\text { B. } 7335 \\
\text { B. } 10785 \\
\text { B. } 13265 \\
\text { B. } 14840 \\
\text { B. } 15640 \\
\text { B. } 15945 \\
\text { B. } 15640 \\
\text { B. } 14840 \\
\text { B. } 13265 \\
\text { B. } 10785 \\
\text { B. } 7335 \\
\text { B. } 2815\end{array}$ & $\begin{array}{l}\text { B. } 2815 \\
\text { B. } 7335 \\
\text { B. } 10785 \\
\text { B. } 13265 \\
\text { B. } 14840 \\
\text { B. } 15640 \\
\text { B. } 15945 \\
\text { B. } 15640 \\
\text { B. } 14840 \\
\text { B. } 13265 \\
\text { B. } 10785 \\
\text { B. } 7335 \\
\text { B. } 2815 \\
\text { F. } 2383 \\
\text { F. } 7975 \\
\text { F. } 13265 \\
\text { F. } 17655 \\
\text { F. } 20605 \\
\text { F. } 21575 \\
\text { F. } 20605 \\
\text { F. } 17655 \\
\text { F. } 13265 \\
\text { F. } 7975 \\
\text { F. } 2383 \\
\text { B. } 2815\end{array}$ & $\begin{array}{l}\text { B. } 15945 \\
\text { B. } 15640 \\
\text { B. } 14840 \\
\text { B. } 13265 \\
\text { B. } 10785 \\
\text { B. } 7335 \\
\text { B. } 2815 \\
\text { F. } 2383 \\
\text { F. } 7975 \\
\text { F. } 13265 \\
\text { F. } 17655 \\
\text { F. } 20605 \\
\text { F. } 21575 \\
\text { F. } 20605 \\
\text { F. } 17655 \\
\text { F. } 13265 \\
\text { F. } 7975 \\
\text { F. } 2383 \\
\text { B. } 2815 \\
\text { B. } 7335 \\
\text { B. } 10785 \\
\text { B. } 13265 \\
\text { B. } 14840 \\
\text { B. } 15640 \\
\text { B. } 15945\end{array}$ & 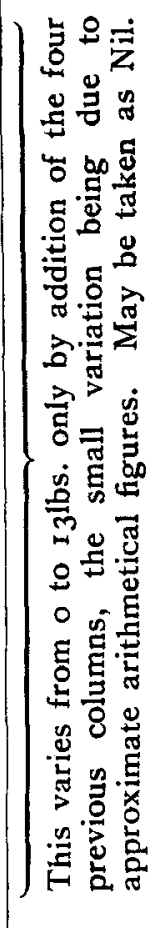 \\
\hline
\end{tabular}




\begin{tabular}{|c|c|c|}
\hline Type of Engine. & $\begin{array}{l}\text { Maximum value of Surg- } \\
\text { ing Force inside and out- } \\
\text { side reciprocating masses } \\
\text { unequal. } \\
\text { lbs. }\end{array}$ & $\begin{array}{l}\text { Maximum value c } \\
\text { Surging Force it } \\
\text { side and outside r } \\
\text { ciprocating masse } \\
\text { equal. } \\
\text { lbs. }\end{array}$ \\
\hline Two inside cylinders ... & \multicolumn{2}{|c|}{ I.732 $W_{\mathrm{i}} r N^{2}$} \\
\hline Two outside cylinders & \multicolumn{2}{|c|}{$1.732 W_{0} r N^{2}$} \\
\hline $\left.\begin{array}{l}\text { Three cylinders with cranks } \\
\text { at } 90^{\circ}, 135^{\circ} \text { and } 135^{\circ}\end{array}\right\}$ & $1.225 r N^{2}\left(1.414 W_{0}-W_{\mathrm{i}}\right)$ & $.507 W r N^{2}$ \\
\hline $\left.\begin{array}{ccc}\text { Three cylinders } & \text { with cranks } \\
\text { at } 120^{\circ} & \ldots & \ldots\end{array}\right\}$ & $1.225 r N^{2}\left(\frac{n-\mathbf{I}}{n} W_{\mathrm{o}}-W_{\mathrm{i}}\right)$ & $\frac{1.225}{n} W r N^{2}$ \\
\hline $\left.\begin{array}{l}\text { Four cylinders with inside } \\
\text { and outside cranks on } \\
\text { same side at } 180^{\circ} \ldots\end{array}\right\}$ & $1.73^{2} r N^{2}\left(W_{\mathrm{i}}-W_{\mathrm{o}}\right)$ & 0 \\
\hline
\end{tabular}

$W_{\mathrm{o}}$ and $W_{\mathrm{i}}=$ outside and inside reciprocating weights. $\quad r=$ cran $n=$ ratio of connecting rod to crank length. $\quad c_{0}$ and $c_{\mathrm{i}}=$ distance in fee 


\section{Maximum Value of Swaying Moment.}

lbs. ft.

$$
\begin{array}{llllll}
K_{2} & W_{\mathrm{i}} & r & N^{2} & c_{\mathrm{i}}
\end{array}
$$

$$
K_{2} W_{0} r N^{2} c_{0}
$$

$$
K_{2} W_{\circ} r N^{2} c_{\mathrm{o}}
$$

$$
K_{3} W_{0} r N^{2} c_{\mathrm{o}}
$$

$$
{ }_{\mathrm{I} .225} r N^{2} W_{\mathrm{o}} c_{\mathrm{o}}\left\{(\mathrm{I}-a b)(\operatorname{Cos} \theta+\operatorname{Sin} \theta)+2 \frac{n_{\mathrm{i}}+a b n_{\mathrm{o}}}{n_{\mathrm{i}} n_{\mathrm{o}}} \operatorname{Cos} 2 \theta\right\}
$$

dius. $\quad N=$ number of revolutions per second of driving wheel. centre line of engine from centre line of outside and inside cylinders respectively. 
Two-cylinder engines and three-cylinder engines with outside cranks at $90^{\circ}$.

$$
\begin{aligned}
& K_{2}=1.946 \text { when } n=5 \\
& K_{2}=1.869 \text { when } n=6.5 \\
& K_{2}=1.828 \text { when } n=8
\end{aligned}
$$

Three-cylinder engines, cranks at $\mathrm{I}_{20} 0^{\circ}$.

$$
\begin{aligned}
& K_{3}=2.269 \text { when } n=5 \\
& K_{3}=2.210 \text { when } n=6.5 \\
& K_{3}=2.180 \text { when } n=8
\end{aligned}
$$

Note re four-cylinder engines (Table VI.).

In the expression given $n_{i}$ and $n_{0}$ are the ratios of connecting rod to crank lengths for the outside and inside motions respectively, and

$$
a=\frac{W_{\mathrm{i}}}{W_{\mathrm{o}}} \text { and } b=\frac{c_{\mathrm{i}}}{c_{\mathrm{o}}}
$$

$\theta$ is the angle which the leading outside crank makes with the horizontal.

As $n_{i}, n_{0}, c_{i}$, and $c_{0}$ all vary, only the general expression given can cover all cases, and its maximum value will depend upon the values of the variable quantities. 


\section{TABLE VII.}

Comparative numerical values from Table VI. in terms of $N^{2}$ when

$W_{\mathrm{i}}=W_{0}=7$ oolbs., i.e., all reciprocating masses equal.

$r=\mathrm{Ift} .\left(24^{n}\right.$ stroke $) c_{\mathrm{o}}=3 \cdot 3^{\mathrm{ft}}$.

$n=7 \quad c_{\mathrm{i}}=\mathrm{I}$. Ift.

$N=$ number of revolutions of driving wheel per second.

\begin{tabular}{|c|c|c|}
\hline & $\begin{array}{c}\text { Maximum } \\
\text { Unbalanced } \\
\text { Surging Force. }\end{array}$ & $\begin{array}{l}\text { Maximum } \\
\text { Unbalanced } \\
\text { Swaying } \\
\text { Moment. }\end{array}$ \\
\hline Two inside cylinders & $\begin{array}{l}\text { lbs. } \\
1212 \mathrm{~N}^{2}\end{array}$ & $\begin{array}{l}\text { lbs. ft. } \\
\text { I423 } \mathrm{N}^{2}\end{array}$ \\
\hline Two outside cylinders & $1212 \mathrm{~N}^{2}$ & $4273 \mathrm{~N}^{2}$ \\
\hline $\begin{array}{l}\text { Three cylinders } \\
\text { cranks at } 90^{\circ}, \quad 135^{\circ} \\
\text { and } 135^{\circ} \text {. }\end{array}$ & $355 \mathrm{~N}^{2}$ & $4273 \mathrm{~N}^{2}$ \\
\hline $\begin{array}{l}\text { Three cylinders with } \\
\text { cranks at } 120^{\circ} \text {. } \\
\text { Four cylinders with in- } \\
\text { side and outside cranks } \\
\text { on the same side at } \\
180^{\circ} \text {. }\end{array}$ & $122.5 \mathrm{~N}^{2}$ & $5084 \mathrm{~N}^{2}$ \\
\hline
\end{tabular}




\section{APPENDIX VIII.}

$a=$ angular velocity of rotation of the engine in swaying. $F=$ force producing swaying in lbs.

$I=$ moment of inertia of the oscillating mass $=\Sigma m L^{2}$, where $L=$ radius of gyration.

$n=$ number of revolutions per second.

$t=$ time of one oscillation.

$\theta=$ angle which the crank makes with the horizontal.

Angular acceleration $\frac{d a}{d t}=\frac{F c}{I}=\frac{F c}{\Sigma m L^{2}}$

But $F c=\frac{W_{\mathrm{o}} v^{2} c}{g r}(\operatorname{Cos} \theta+\operatorname{Sin} \theta)$

$$
=\frac{W_{0} c}{g} 4 \pi^{2} n^{2} r(\operatorname{Cos} \theta+\operatorname{Sin} \theta)
$$

$\therefore \frac{d a}{d t}=\frac{W_{0} c}{g I} 4 \pi^{2} n^{2} r(\operatorname{Cos} \theta+\operatorname{Sin} \theta)$

But $\theta=2 \pi n t$, from which $d t=\frac{d \theta}{2 \pi n}$

$$
\begin{aligned}
\therefore \frac{d a}{d t} & 2 \pi n \frac{d a}{d \theta}=\frac{F c}{I} \\
\therefore \frac{d a}{d \theta} & =\frac{\mathrm{I}}{2 \pi n} \frac{F c}{I}
\end{aligned}
$$

and $d a=\frac{I}{2 \pi n} \frac{W_{0} c}{I g} 4 \pi^{2} n^{2} r(\operatorname{Cos} \theta+\operatorname{Sin} \theta) d \theta$

$$
=\frac{W_{\mathrm{o}} c}{I g} 2 \pi n r(\operatorname{Cos} \theta+\operatorname{Sin} \theta) d \theta
$$

$$
\therefore a=\frac{W_{\circ} c}{I g} 2 \pi n r \int(\operatorname{Cos} \theta+\operatorname{Sin} \theta) d \theta
$$

integrating

$$
\alpha=\frac{W_{0} c r}{I g} 2 \pi n r(\operatorname{Sin} \theta-\operatorname{Cos} \theta)
$$

Moreover, the angular acceleration $a=\frac{\text { arc described }}{\text { time }}$ $=\frac{d s}{d t}$ 
$s$ being arc of which the radius is unity, i.e., at one foot from the centre of gravity, 8 will be measured in feet.

$$
\begin{aligned}
& d s=a d t \\
& \therefore s=\int a d t=\int a \frac{d \theta}{2 \pi n} \\
& =\int_{45^{\circ}}^{135^{\circ}} \frac{\mathrm{I}}{2 \pi \mathrm{n}} \frac{W_{0} c}{\mathrm{Ig}} 2 \pi n r(\operatorname{Sin} \theta-\operatorname{Cos} \theta) d \theta \\
& =-\frac{W_{0} c r}{I g}(\operatorname{Cos} \theta+\operatorname{Sin} \theta){ }_{45^{\circ}}^{135^{\circ}} \\
& \operatorname{Cos} 135^{\circ}=-\frac{1}{\sqrt{2}} \cdot \operatorname{Sin} 135^{\circ}=\frac{1}{\sqrt{2}} \\
& \operatorname{Cos} 45^{\circ}=+\frac{I}{\sqrt{2}} \quad \text { Sin } 45^{\circ}=\frac{1}{\sqrt{2}} \\
& \therefore 8=-\sqrt{\frac{2}{2}} \frac{W_{0} c r}{I g}=-\frac{1.414 W_{0} c r}{I g} \\
& \text { Since } I=\operatorname{mass} \times L^{2}=\frac{T}{g} L^{2} \\
& s=-\frac{1.414 W_{0} c r}{T L^{2}}
\end{aligned}
$$

The negative sign is merely one of direction of sway. On the other side of the engine the value of $s$ is + .

The above value of the amplitude of sway (s) does not take into account the effect of the obliquity of the connecting rod. This may be allowed for by slightly increasing the coefficient r.4I4. The increase will be slightly less than one quarter of the increase in the swaying force, but taking it as one quarter, the coefficient will become

I. $45^{8}$ if the rod is 5 times the length of the crank

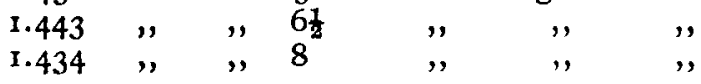

The increase above I.4I4, therefore, varies from $3 . \mathrm{I}$ per cent. to 1.4 per cent. for the above values, and the amplitude of sway correspondingly increased.

The coefficient of equation $\left(c_{2}\right)$ in which $\mathrm{T}$ is expressed as $T_{0}$ tons will become $.005^{1} 5$ for rod $=5$ cranks, and $.005^{\mathrm{r}}$ for rod $=6 \frac{1}{2}$ cranks, and .00507 for rod $=8$ cranks. 

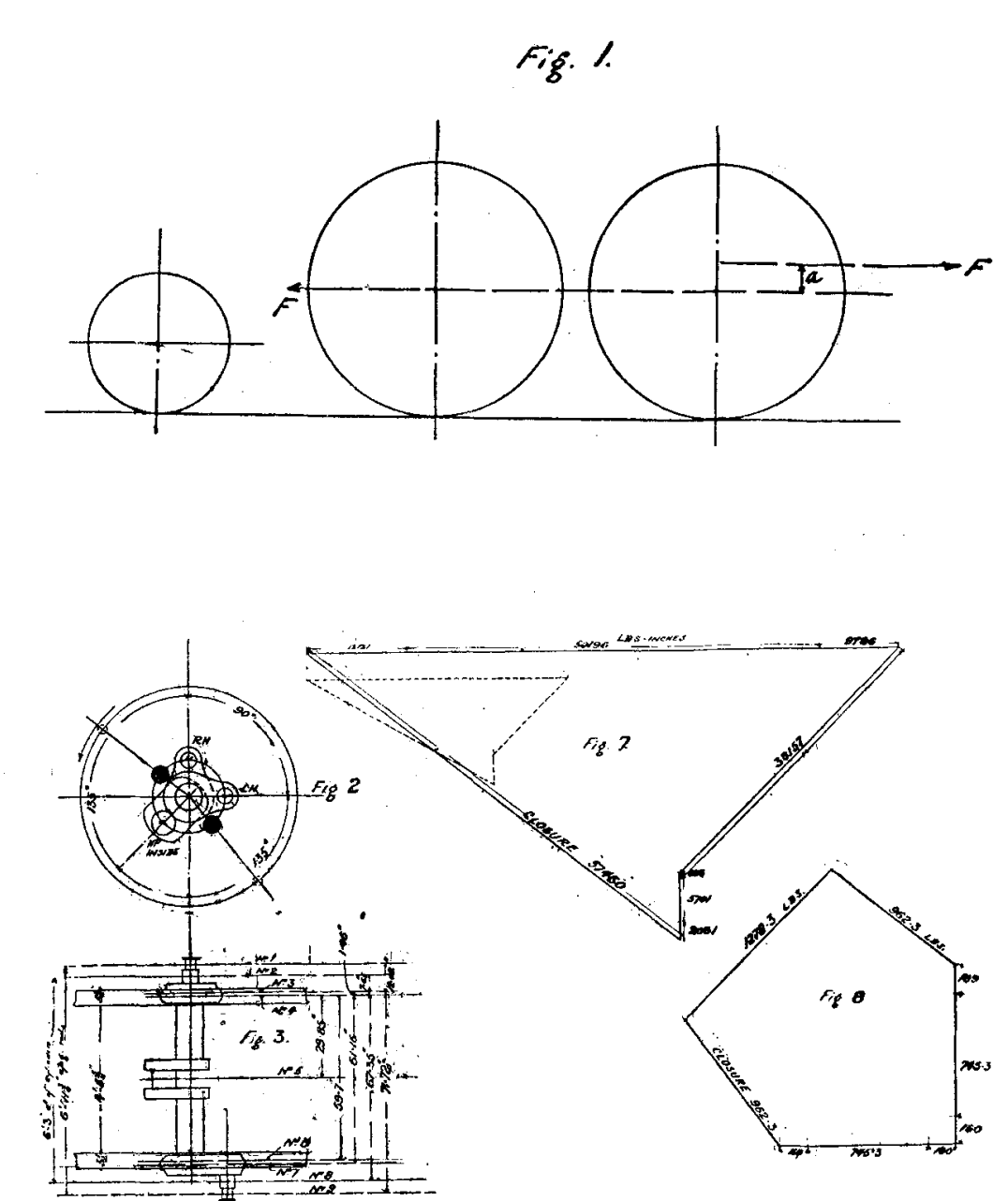

Figs. $2,3,7$, and 8.
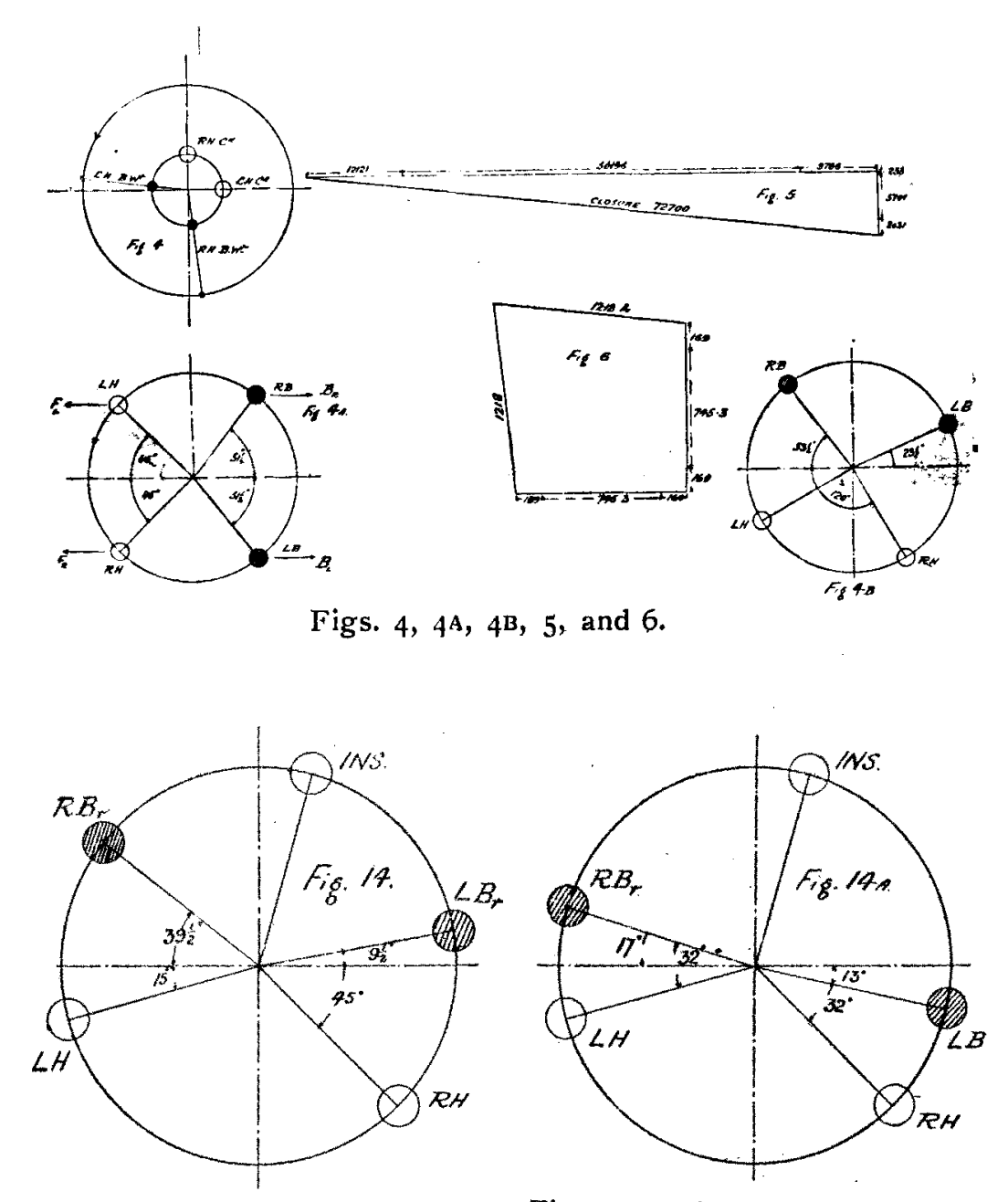

Figs. 14 and I4A.

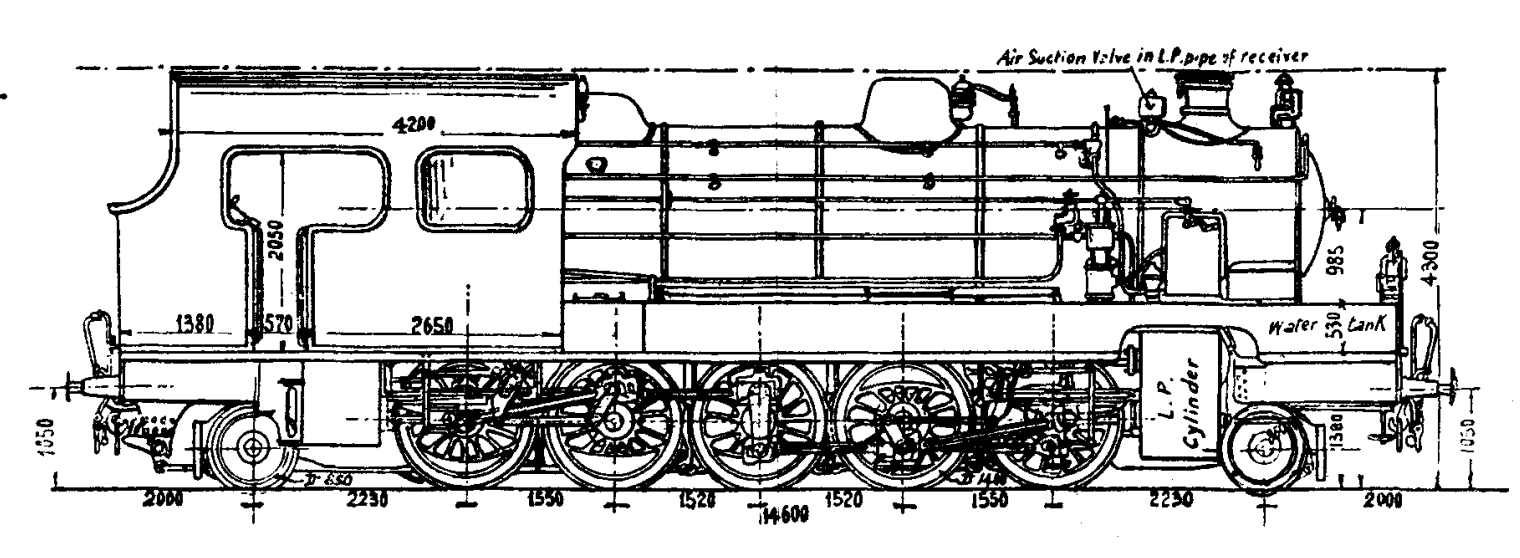

BREDA TEN.COUPLEO COMPOUNO LOCOMOTIVE

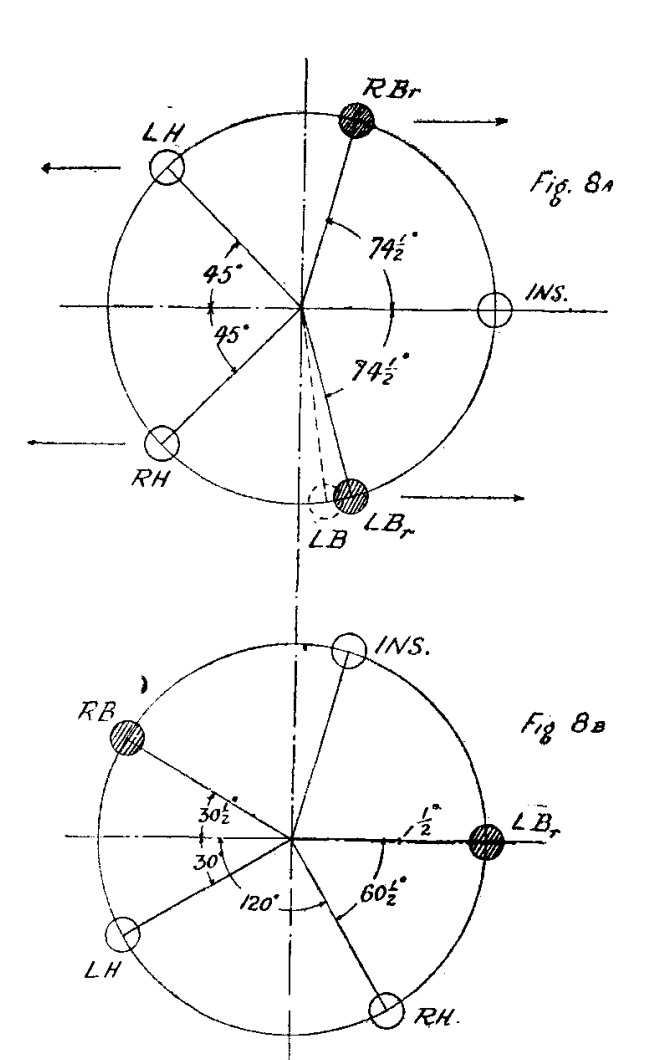

Figs. $8 \mathrm{~A}$ and $8 \mathrm{~B}$.

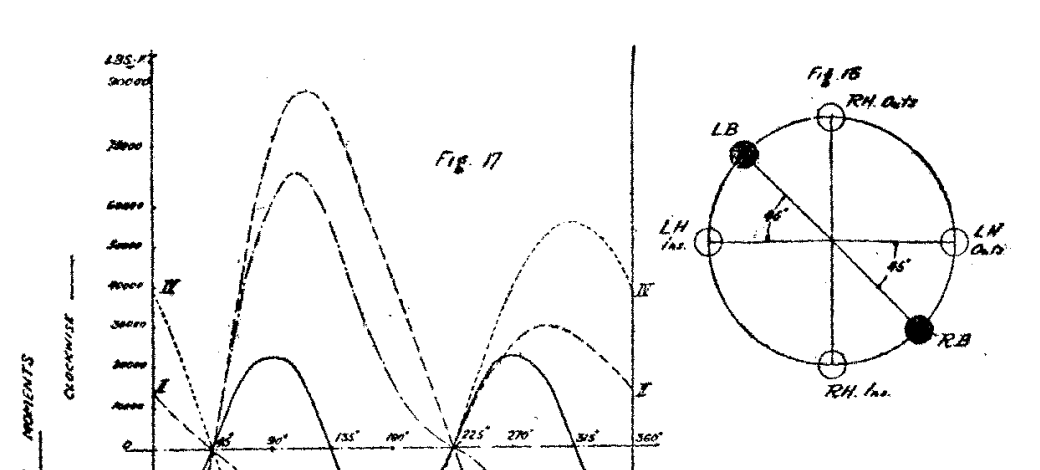

Figs. 17 and 16.

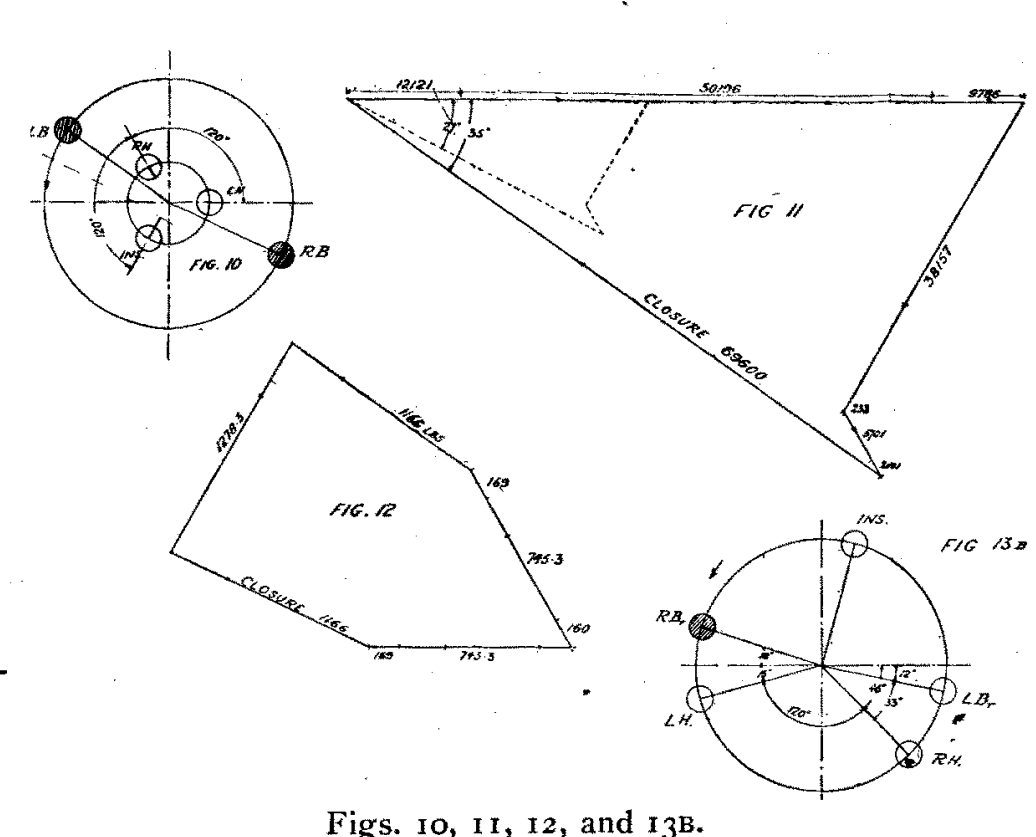

Figs. 10, 11,12 , and $\mathrm{I}_{3} \mathrm{~B}$.

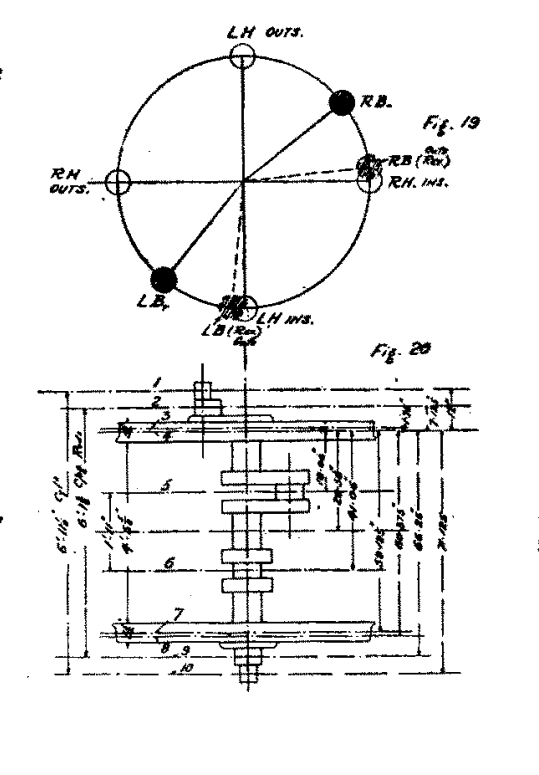

Figs. 18, 19, 20, and

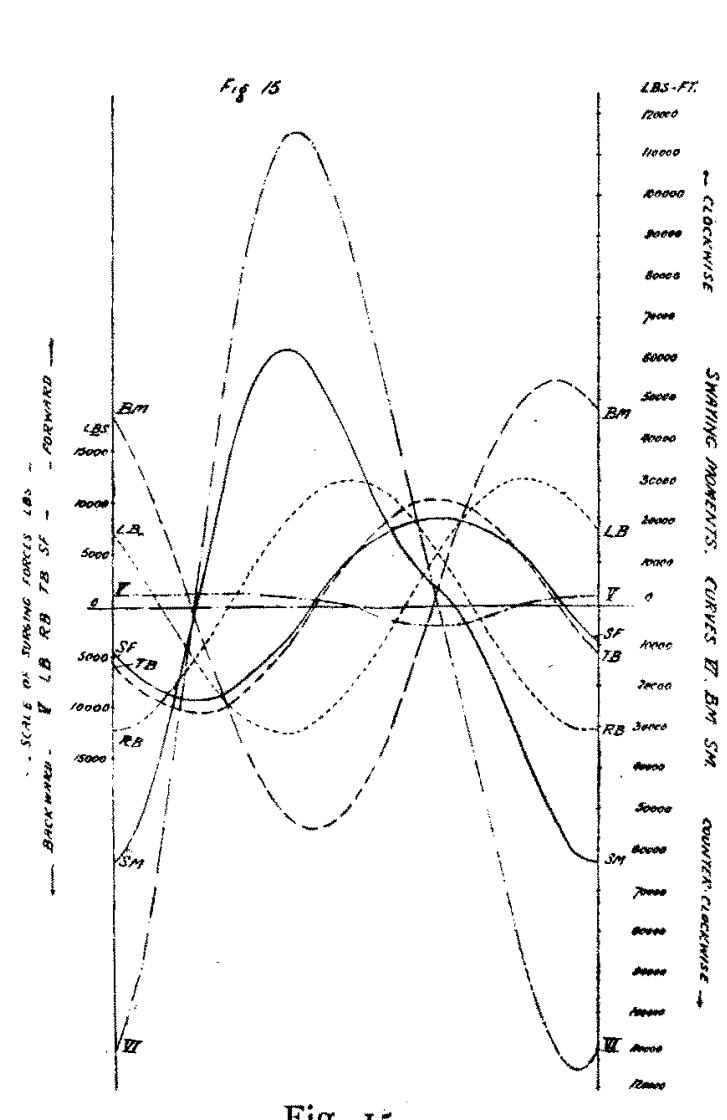

Fig. 15.
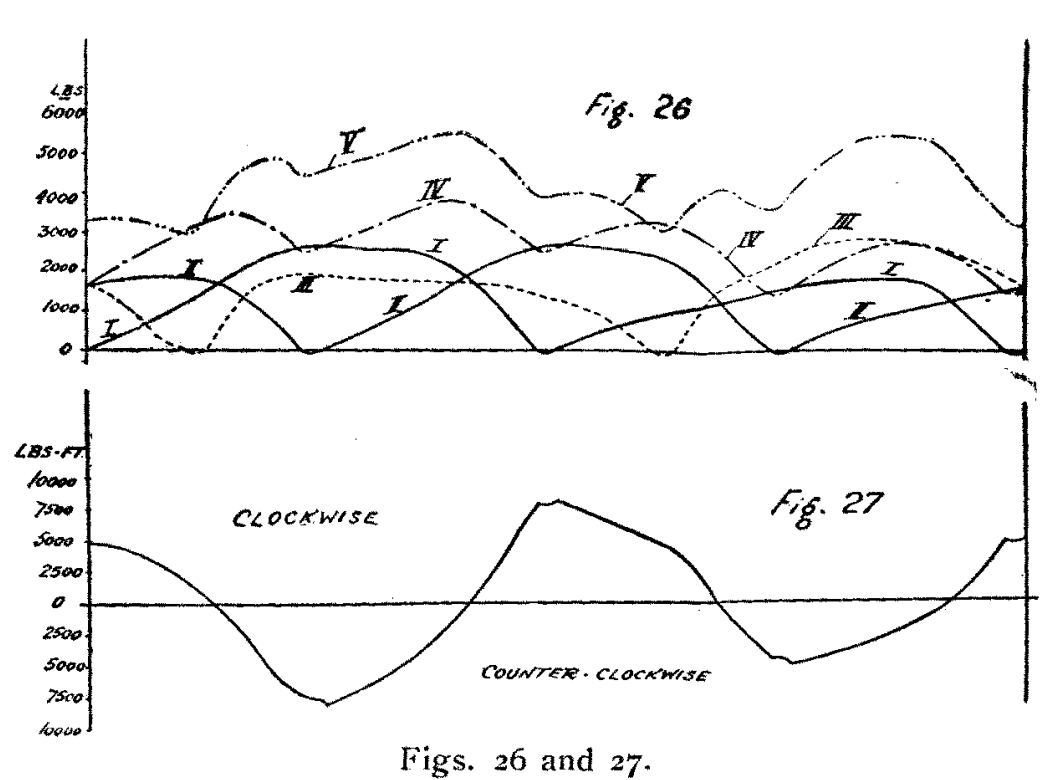


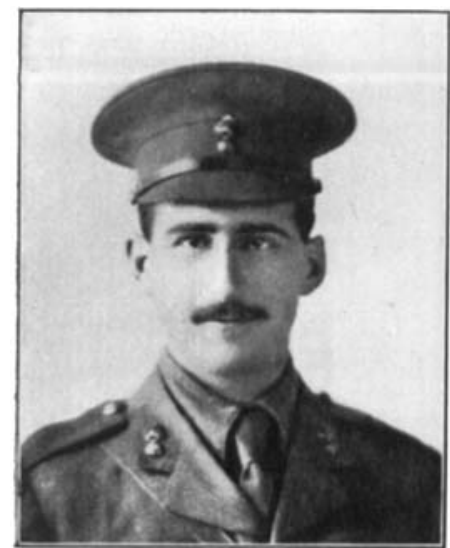

H. Crosin.

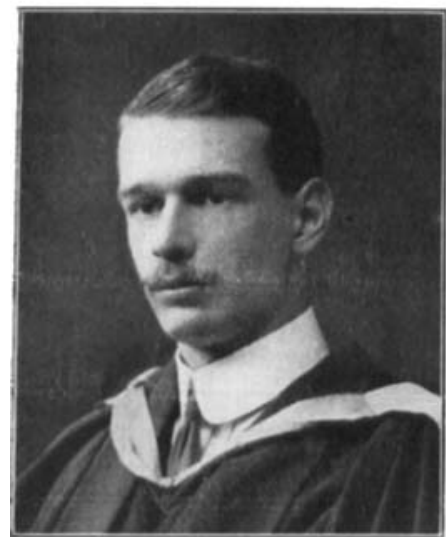

F. I.. Bassktt, B.Sc., I.I.C.

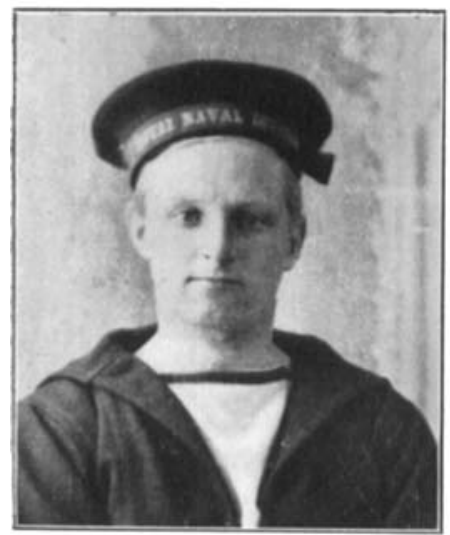

R. F. M. Eardeley, StUd, I.C.E.

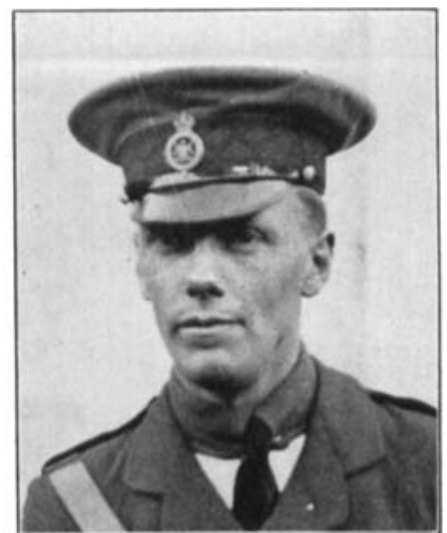

E. B. WALKER.

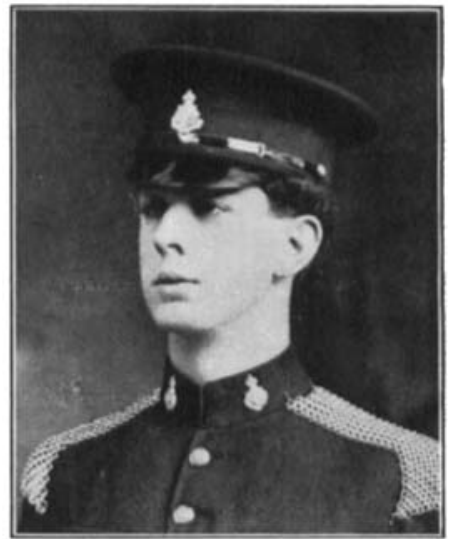

G. I. Siss.

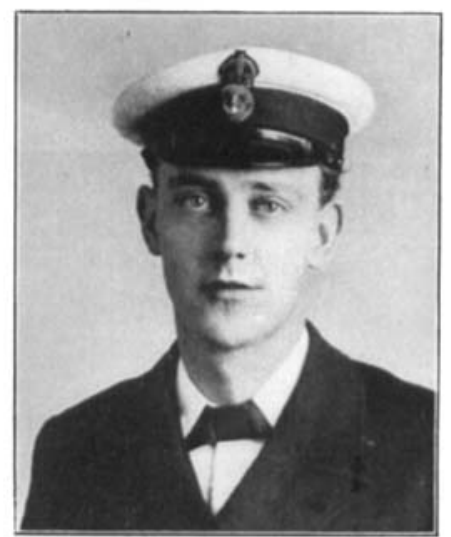

F. W. Сroок. 